\title{
Prion agent diversity and species barrier
}

\author{
Vincent BÉRINGUE ${ }^{1 *}$, Jean-Luc VILOTTE ${ }^{2}$, Hubert LAUDE $^{1}$ \\ ${ }^{1}$ Institut National de la Recherche Agronomique (INRA), UR892, Virologie et Immunologie Moléculaires, \\ F-78350 Jouy-en-Josas, France \\ ${ }^{2}$ INRA, UR339, Génétique Biochimique et Cytogénétique, F-78350 Jouy-en-Josas, France
}

(Received 25 March 2008; accepted 30 May 2008)

\begin{abstract}
Mammalian prions are the infectious agents responsible for transmissible spongiform encephalopathies (TSE), a group of fatal, neurodegenerative diseases, affecting both domestic animals and humans. The most widely accepted view to date is that these agents lack a nucleic acid genome and consist primarily of $\mathrm{PrP}^{\mathrm{Sc}}$, a misfolded, aggregated form of the host-encoded cellular prion protein $\left(\mathrm{PrP}^{\mathrm{C}}\right)$ that propagates by autocatalytic conversion and accumulates mainly in the brain. The BSE epizooty, allied with the emergence of its human counterpart, variant CJD, has focused much attention on two characteristics that prions share with conventional infectious agents. First, the existence of multiple prion strains that impose, after inoculation in the same host, specific and stable phenotypic traits such as incubation period, molecular pattern of $\mathrm{PrP}^{\mathrm{Sc}}$ and neuropathology. Prion strains are thought to be enciphered within distinct $\operatorname{PrP}^{\mathrm{Sc}}$ conformers. Second, a transmission barrier exists that restricts the propagation of prions between different species. Here we discuss the possible situations resulting from the confrontation between species barrier and prion strain diversity, the molecular mechanisms involved and the potential of interspecies transmission of animal prions, including recently discovered forms of TSE in ruminants.
\end{abstract}

prion / strain / misfolding / species barrier / PrP

Table of contents

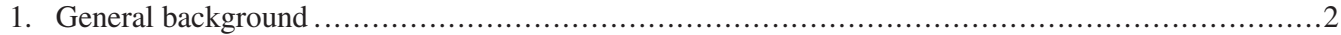

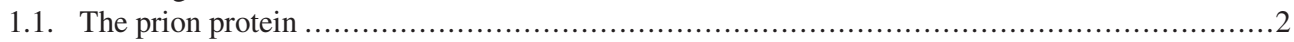

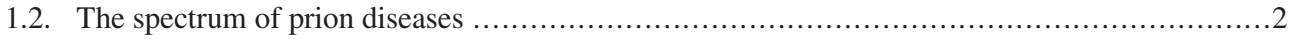

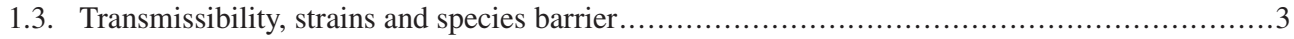

2. Biological parameters controlling the efficiency of cross-species transmission ....................... 4

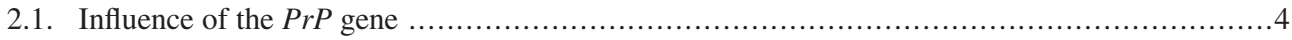

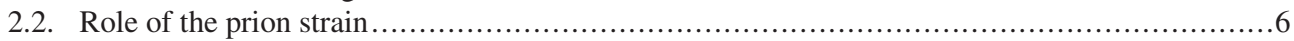

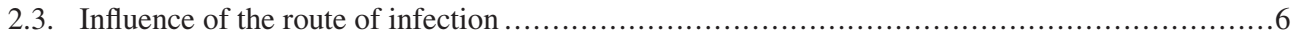

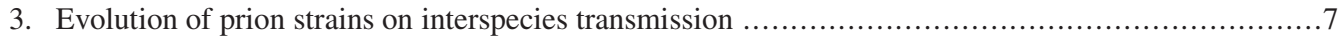

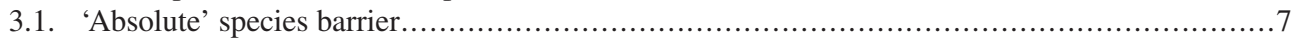

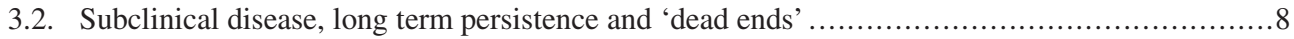

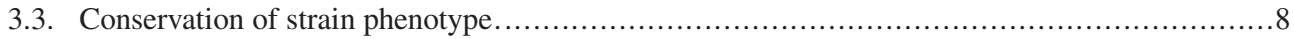

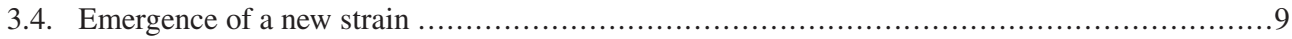

3.4.1. Lessons from studies in rodent models ............................................ 10

3.4.2. New strains can emerge from classical and atypical BSE agents....................... 10

4. Insight into the molecular determinism of the interspecies barrier................................... 12

4.1. Molecular conformation of $\operatorname{PrP}^{\mathrm{Sc}}$ during cross-species transmission ......................... 12

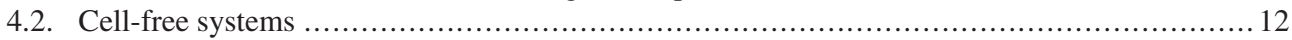

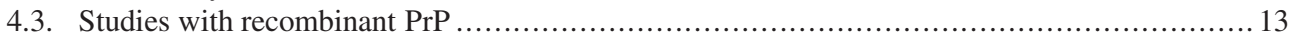

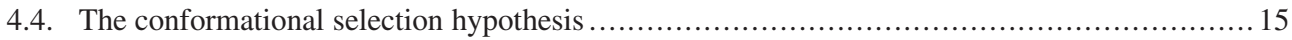

*Corresponding author: vincent.beringue@jouy.inra.fr 
5. Strain diversity and potential of interspecies transmission of animal prions …..................... 17

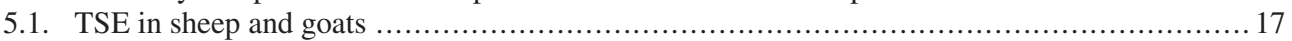

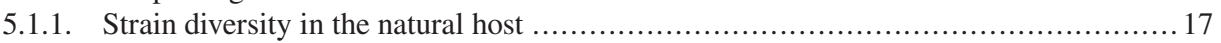

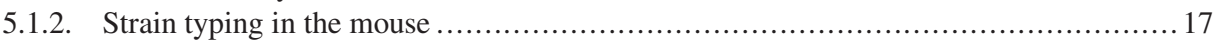

5.1.3. Assessment of scrapie strain diversity with transgenic mouse models .................. 18

5.1.4. Potential of interspecies transmission of scrapie ....................................... 18

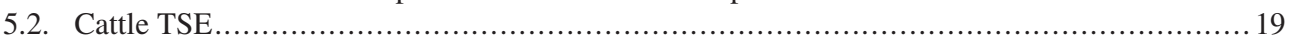

5.2.1. Diversity of TSE strains in cattle ....................................................... 19

5.2.2. Potential of interspecies transmission of atypical cattle TSE............................ 19

5.2.3. Atypical BSE in cattle, the origin of epizootic BSE? .................................. 20

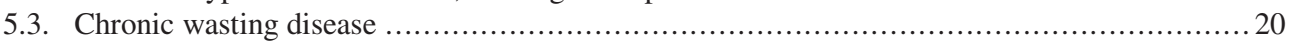

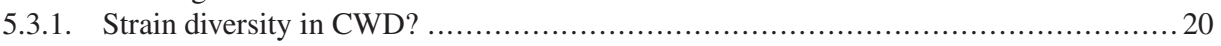

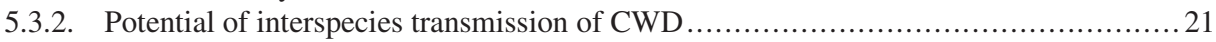

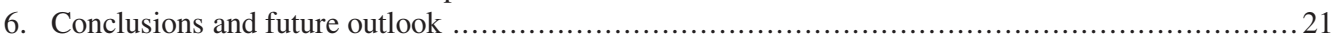

\section{GENERAL BACKGROUND}

\subsection{The prion protein}

Mammalian prion diseases or transmissible spongiform encephalopathies (TSE) form a group of related, invariably fatal neurodegenerative disorders of both animals and humans. The brain pathology consists of spongiosis, astrocytosis, neuronal loss and neural tissue from affected individuals contains an infectious agent, the prion, setting these diseases apart from other neurodegenerative diseases. Prion replication is thought to involve in essence the self-perpetuating conversion of the host-encoded cellular prion protein $\left(\mathrm{PrP}^{\mathrm{C}}\right)$ into a misfolded form $\left(\mathrm{PrP}^{\mathrm{Sc}}\right)$ that tends to aggregate and may be neurotoxic (for reviews $[1,157])$. Prion replication may also occur in lymphoid tissues but is there poorly if not pathogenic (for review [126], [133]). $\mathrm{PrP}^{\mathrm{C}}$ is a protein with two variably occupied glycosylation sites. It is attached at the outer of the plasma membrane by a glycosylphosphatidylinositol anchor. Its secondary structure is rich in alpha-helix and the protein is likely to be in a monomeric state in mild detergents. While its precise physiological function has not been assigned, $\operatorname{PrP}^{C}$ is essential for prion replication and neurotoxicity to occur [57, 129]. Upon infection, $\mathrm{PrP}^{\mathrm{C}}$ is refolded - without apparent post-translational modification - into beta-sheet - rich $\mathrm{PrP}^{\mathrm{Sc}}$, initially in the presence of exogenous $\mathrm{PrP}^{\mathrm{Sc}}$ and then by an autocatalytic process. It leads to the formation of aggregates, sometimes of amyloid type, that can be differentiated from $\operatorname{PrP}^{\mathrm{C}}$ because of their partial resistance to protease digestion and of their insolubility into non-denaturing detergents [153]. Proteinase K, the most commonly used protease, digests $\operatorname{PrP}^{\mathrm{C}}$ and causes $\mathrm{PrP}^{\mathrm{Sc}}$ cleavage around residue 90, leading to a protein with a molecular weight of 27 to $30 \mathrm{kDa}$, termed $\mathrm{PrP}^{\mathrm{res}}$ or $\mathrm{PrP}^{27-30}$. A notion to be kept in mind is that the abnormal PrP species that accumulates in infected tissues may have variable degrees of proteinase $\mathrm{K}$ resistance. Creutzfeldt-Jakob disease-affected patients, for instance, have been reported to accumulate protease-sensitive $\mathrm{PrP}^{\mathrm{Sc}}$ in notable amounts, as detected by a conformationdependent assay on brain tissue [171]. Accordingly, the terms $\operatorname{PrP}^{\text {res }}$ and $\operatorname{PrP}^{\mathrm{Sc}}$ will be used for distinct purposes throughout this review.

\subsection{The spectrum of prion diseases}

Animal TSE encompass scrapie in sheep and goats, bovine spongiform encephalopathy (BSE) or ' $m a d$ cow' disease in cattle, chronic wasting disease (CWD) in cervids and transmissible mink encephalopathy (TME). Creutzfeldt-Jakob disease (CJD) is the most common human prion disease (for review [56]). It is unique among other diseases because of a triple possible origin: sporadic, genetic or acquired. About $85 \%$ of CJD cases are sporadic, affecting elderly people with an annual worldwide incidence of 1-2 per million [116]. The aetiology of sporadic CJD is currently unknown. It is hypothesized that 
somatic mutation in the $\operatorname{Pr} P$ gene or a rare, stochastic event of spontaneous conversion of $\mathrm{PrP}^{\mathrm{C}}$ into $\mathrm{PrP}^{\mathrm{Sc}}$ may be at the origin of $\mathrm{PrP}^{\mathrm{Sc}}$ accumulation in the brain of these patients [202]. The other cases are either familial, linked to pathogenic mutations in the prion protein gene, or iatrogenic, resulting from exposure to CJD-contaminated, extractive growth hormone or medical devices. In 1996 a new human prion disease was identified in the United-Kingdom with a much younger age of onset, a longer clinical course and a distinct neuropathology as compared to classical CJD [205]. Several lines of evidence link the emergence of this new CJD variant (vCJD) to the BSE epizooty [56]. Since 1996, over 200 individuals have developed vCJD in Europe ${ }^{1}$. More than two million BSEinfected cattle have entered the human food chain during the 1980s' and 1990s'. Although mathematical modeling suggests that a huge epidemic is unlikely [195], caution must be exerted because the prevalence of the infection seems greater than the disease incidence, reflecting the strong propensity of the vCJD agent to accumulate in peripheral tissues and blood without causing any harm [4, 22, 93, 99, 123]. The risk of human-to-human transmission of the vCJD agent is undoubtedly a growing public-health concern.

\subsection{Transmissibility, strains and species barrier}

Intra-species transmission of the TSE agent was first demonstrated with sheep scrapie in the 1930s' [61]. Generally cross-species transmission, typically to laboratory rodents, is less efficient than intra-species transmission as evidenced by an extended incubation time and incomplete attack rate. In general, this so-called 'species barrier' is abrogated after a few subpassages (usually 2-3), reflecting prion adaptation to its new host. This has led to the development of rodent models that recapitulate most of the physiopathological features observed in a natural prion disease

\footnotetext{
${ }^{1}$ Variant Creutzfeld-Jakob disease current data [online] http://www.cjd.ed.ac.uk/vcjdworld.htm [consulted 23/03/2008].
}

(see Tab. I for a brief description of these models and their origin). In seminal experiments, Dickinson et al. established that distinct prion strains could be raised and propagated in different lines of inbred mice upon serial adaptation of sheep or goat scrapie isolates. Such mouse-adapted strains were stably differentiable according to the incubation time and the distribution and severity of vacuolation in the brain (Fig. 1, for review [37]). These specific phenotypic traits cannot be encoded by differences in the $\operatorname{PrP}^{\mathrm{C}}$ sequence since these strains were propagated in inbred mice homozygous for the $\operatorname{Pr} P$ gene. A possible nucleic acid component in the infectious agent has remained elusive so far [172]. The now widely accepted 'protein-only' hypothesis proposes that these strain-specific properties are enciphered within biologically active, structural differences in the $\operatorname{PrP}^{\mathrm{Sc}}$ molecules. Accumulating evidence argue for the existence of variable $\mathrm{PrP}^{\mathrm{Sc}}$ conformations. Indeed prion strains are associated with $\mathrm{PrP}^{\mathrm{Sc}}$ species that differ in their biochemical properties (Tab. II, Fig. 1). This includes the electrophoretic mobility after proteinase $\mathrm{K}$ digestion that reflects a different access to the $\mathrm{N}$-terminal region of the PrP molecule, the ratio of glycoforms or the stability toward denaturing agents. The demonstration that in cell-free assays the $\mathrm{PrP}^{\mathrm{C}}$ conversion product retains a $\mathrm{PrP}^{\mathrm{res}}$ molecular signature similar to that of the seeding material (see Sect. 4.2) further suggested that prion strain specificity might be encoded at the level of protein conformation, particularly $\mathrm{PrP}^{\mathrm{Sc}}$ tertiary structure.

The recent emergence of the new vCJD strain in humans has highlighted the ability of prions to cross and propagate in other species and the risk it might cause for human health. One of the aims of this review is to show that the prion strain variation, potentially inherent to the conformational flexibility of the prion protein, combined with the ability of these agents to infect foreign hosts, creates a complex situation that remains currently difficult to apprehend. This is not only appealing scientifically but also has important implications in terms of safety of food, drugs and blood products. We will also present advances 
Table I. Origin and diversity of experimental TSE strains in rodents.

\begin{tabular}{|c|c|c|c|c|}
\hline Name & Origin & Passage in intermediate species & Host & References \\
\hline ME7 & Sheep scrapie ${ }^{\mathrm{a}}$ & No & Mouse $(P r n-a)$ & {$[33,36,37,212]$} \\
\hline $87 \mathrm{~A}$ & Sheep scrapie ${ }^{\mathrm{a}}$ & No & Mouse (Prn- $a)$ & [32] \\
\hline $221 \mathrm{C}$ & Sheep scrapie ${ }^{a}$ & No & Mouse (Prn-a) & [36] \\
\hline $87 \mathrm{~V}$ & Sheep scrapie ${ }^{\mathrm{a}} \mathrm{SSBP} / 1^{\mathrm{b}}$ & No, goats ${ }^{c}$ & Mouse $(P r n-b)$ & {$[33,36]$} \\
\hline $79 \mathrm{~A}$ & $\mathrm{SSBP} / 1^{\mathrm{b}}$ & goats $^{\mathrm{c}}$ & Mouse (Prn-a) & [33] \\
\hline $79 \mathrm{~V}$ & $\mathrm{SSBP} / 1^{\mathrm{b}}$ & goats $^{\mathrm{c}}$ & Mouse $(P r n-b)$ & [33] \\
\hline $139 \mathrm{~A}^{\mathrm{d}}$ & $\mathrm{SSBP} / 1^{\mathrm{b}}$ & goats ${ }^{\mathrm{c}}$ & Mouse (Prn-a) & [52] \\
\hline $22 \mathrm{C}$ & $\mathrm{SSBP} / 1^{\mathrm{b}}$ & No, goats ${ }^{\mathrm{e}}$ & Mouse $($ Prn- $a)$ & [33] \\
\hline $22 \mathrm{H}$ & Uncloned 22C & No, goats ${ }^{\mathrm{e}}$ & Mouse $(P r n-b)$ & [33] \\
\hline $22 \mathrm{~L}$ & $\mathrm{SSBP} / 1^{\mathrm{b}}$ & No & Mouse (Prn-a) & [33] \\
\hline $22 \mathrm{~A}$ & $\mathrm{SSBP} / 1^{\mathrm{b}}$ & No & Mouse $(P r n-b)$ & {$[33,69]$} \\
\hline $22 \mathrm{~F}$ & Cloned 22A & No & Mouse (Prn- $a)$ & [33] \\
\hline $301 C^{f}$ & BSE & Direct or not & Mouse (Prn- $a)$ & {$[31,35]$} \\
\hline $301 \mathrm{~V}$ & BSE & Direct or not & Mouse $(P r n-b)$ & {$[31,35]$} \\
\hline $139 \mathrm{H}$ & Cloned 139A & No & Syrian hamster & [108] \\
\hline $263 \mathrm{~K}^{\mathrm{g}}$ & $\mathrm{SSBP} / 1^{\mathrm{b}}$ & goats $^{\mathrm{c}}$, mice, rats & Syrian hamster & [105] \\
\hline ME7-H & Cloned ME7 & No & Syrian hamster & [110] \\
\hline$H Y^{h}$ & $\mathrm{TME}^{\mathrm{i}}$ & No & Syrian hamster & [23] \\
\hline DY & $\mathrm{TME}^{\mathrm{i}}$ & No & Syrian hamster & [23] \\
\hline
\end{tabular}

${ }^{a}$ Field isolate; ${ }^{b} \mathrm{SSBP} / 1$ : sheep scrapie brain pool $1 ;{ }^{\mathrm{c}}$ Passage of SSBP/1 through goats: 'drowsy' goat source; ${ }^{\mathrm{d}}$ Also termed Chandler or RML; ${ }^{\mathrm{e}}$ Passage of SSBP/1 through goats: 'scratching' goat source; ${ }^{\mathrm{f}}$ Not known if $301 \mathrm{C}$ yields to $301 \mathrm{~V}$ in Prn- $b$ mice; ${ }^{\mathrm{g}} \mathrm{Sc} 237$ is a subclone of $263 \mathrm{~K} ;{ }^{\mathrm{h}}$ Similar to 263K?; ${ }^{\mathrm{i}} \mathrm{TME}$ : Stetsonville isolate.

in the recently discovered prion strains in ruminant and the potential implications for public health.

\section{BIOLOGICAL PARAMETERS CONTROLLING THE EFFICIENCY OF CROSS-SPECIES TRANSMISSION}

\subsection{Influence of the $\operatorname{Pr} P$ gene}

The PrP sequence as well as the tridimensional $\mathrm{PrP}^{\mathrm{C}}$ structure [208] is highly conserved among mammalian species, yet prions do not jump readily from one species to another. Minimal amino acid divergences may have a major impact on the transmission efficiency. It has been known for a long time that within the same species, susceptibility to TSE is tightly controlled by natural variations in the PrP sequence. For example, sheep breeds exhibit variable susceptibilities to experimental or natural scrapie, and polymorphisms at codons 136, 154 and 171 of the ovine $\operatorname{Pr} P$ gene are particularly important [79, 80]. A/V/T, R/H/L and R/H/Q/K can be encoded at these positions, respectively. Sheep homozygous for the $\mathrm{V}_{136} \mathrm{R}_{154} \mathrm{Q}_{171}$ (VRQ) allele are highly susceptible to classical scrapie whereas sheep homozygous for $A_{136} R_{154} R_{171}$ (ARR) exhibit pronounced resistance $[16,72]$. The latter characteristic has been rarely overcome [84]. Such a tight control of scrapie prion replication by ovine PrP polymorphisms can be reproduced both at the cellular level, in infected cell cultures [168], and in cell-free assays [29], arguing for a preponderant role of the PrP sequence over other genetic factors in sheep breeds. Polymorphism at residue 129 (M or V) of human PrP similarly influences susceptibility to human TSE. Homozygosity is a predisposing factor to the development of sporadic and acquired forms of CJD. Strikingly, all clinical cases of vCJD have been homozygous for methionine at codon 129 so far (for review [56, 202]).

Early studies suggested that the crossspecies barrier resides essentially in PrP primary structure differences between the host and donor species. In seminal experiments, Scott et al. [173] abrogated the recognized 
A

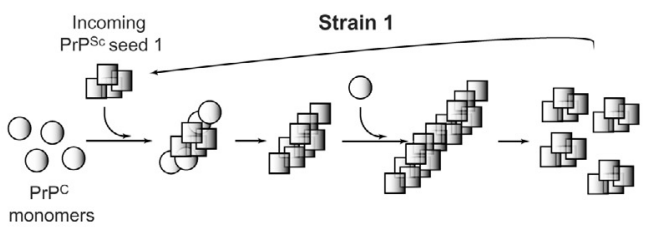

Binding Conversion Polymerisation Fragmentation Generation of
new seeds

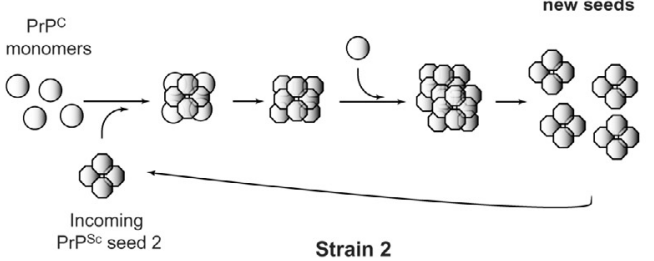

B
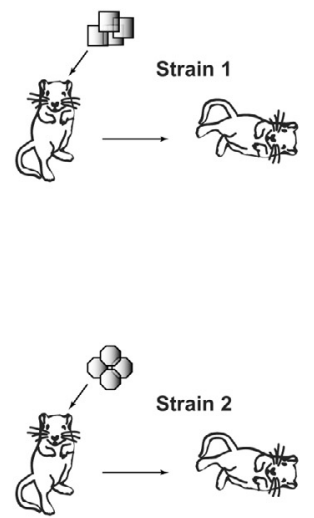

(1)
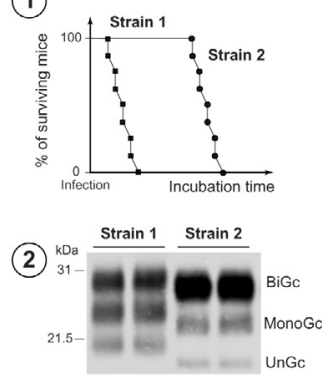

(3)

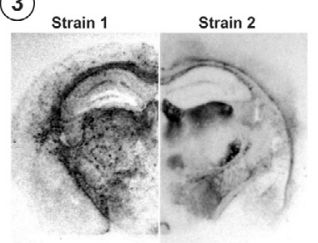

(4)

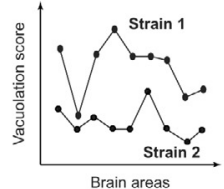

Figure 1. Strain-specified propagation of prions. (A) According to the nucleated polymerization model [89, 131], the mechanisms of prion replication may proceed through the binding of monomeric $\operatorname{PrP}^{\mathrm{C}}$ (possibly a partially unfolded species of the protein) onto an aggregated $\mathrm{PrP}^{\mathrm{Sc}}$ seed, followed by in situ conversion into a conformation similar to $\mathrm{PrP}^{\mathrm{Sc}}$. Incorporation of the $\mathrm{PrP}^{\mathrm{C}}$ molecules constantly renewed by the host concurs to further growing of the aggregate. Degradation may also happen (not shown). At a point, the polymer may divide to generate new seeds and amplify the replication in an autocatalytic manner. According to the conformational hypothesis, conformationally distinct, faithfully perpetuating PrP seeds would account for the existence of different prion strains in a given host. (B) Upon experimental inoculation of susceptible animals with defined genetic background, prion strains exhibit specific traits ('phenotype') such as: (1) attack rate and incubation time, (2) $\mathrm{PrP}^{\mathrm{res}}$ banding pattern in immunoblot (size of the protease-resistant fragments and relative ratio of the glycoforms, $(\mathrm{Gc})$ ), (3) regional distribution of $\mathrm{PrP}^{\mathrm{res}}$ species within the brain as shown here by histoblots of coronal sections, (4) distribution and intensity of vacuolation in standardized brain areas. These features can be indefinitely maintained upon serial passaging in the same host.

resistance of the mouse to hamster scrapie [106] by expressing hamster $\operatorname{PrP}^{\mathrm{C}}$ in transgenic mice. This apparent lack of species barrier after homotypic transmission - i.e. when the host expresses a $\operatorname{Pr} P$ gene identical to that of the infecting species - has led to the development of a long list of mice transgenic for sheep [60, 197, 203], bovine [20, 41, 48, 175], human [5, 22, 113, 190], cervid [30, 82, 113, 117, 134, 188] and mink [206] PrP. Most of such lines were obtained by additional transgenesis, and have an endogenous $\operatorname{PrP}$ null $\left(\operatorname{Pr} P^{0 / 0}\right)$ background, in order to avoid any interfering effect of the resident murine $\operatorname{PrP}$ gene [39, 190]. An inverse correlation between the length of survival time and expression level of the transgene in the brain has been noticed in mice transgenic for mouse, hamster and sheep PrP $[156,197]$. Some transgenic lines have been established by a gene replacement method (for review [44]). PrP sequence identity between the transgenic host and donor usually lead to an enhanced susceptibility to TSE as compared to wild-type 
Table II. An overview of the criteria used to experimentally distinguish prion strains.

\begin{tabular}{lll}
\hline Phenotype & Technique / Protocol used & References \\
\hline Incubation period in recipient animals & Measure of incubation time or survival time between & {$[37,154]$} \\
& inoculation and disease onset or terminal stage & \\
Disease presentation & Behavioral tests & {$[67]$} \\
& Clinical signs in animals & {$[24,104]$} \\
Biochemical properties of PrPSc & Protease-induced cleavage (Proteinase K / Thermolysin) & {$[143,153]$} \\
& Ratio of glycosylated species & {$[54,184]$} \\
& Denaturation with chaotropes & {$[148]$} \\
& Resistance to heat & {$[185]$} \\
& Ratio of native versus denatured PrP & {$[169]$} \\
& Infrared spectroscopy, Circular dichroism, & {$[51,144,186]$} \\
& Fourier-transformed infrared spectroscopy & \\
PrP ${ }^{S c}$ distribution in brain & Immunohistochemistry / Histoblots & {$[34,90]$} \\
Nature of PrPSc deposits & Histology, Congo red or thioflavin S/T binding & {$[122,155]$} \\
& PrP deposits epitope mapping & {$[102]$} \\
Distribution \& intensity of spongiosis & Other binding probes & {$[180]$} \\
Tropism & Histology (so-called 'lesion profile') & {$[76]$} \\
& For lymphoreticular system & {$[109]$} \\
& For cultures & {$[58,127]$} \\
\hline
\end{tabular}

mice. Moreover, in various instances, the TSE agent original properties, in particular $\mathrm{PrP}^{\mathrm{Sc}}$ molecular profile, appeared to be essentially maintained in the infected transgenic host (see also Sect. 5).

\subsection{Role of the prion strain}

Prion strain type can play a pivotal role as the host PrP sequence in cross-species transmission events. This has been brought to light by the apparent capacity of the BSE agent to transmit with relative ease to other species such as exotic ruminants, cats and humans without obvious phenotypic alteration, based on both $\mathrm{PrP}^{\mathrm{res}}$ profile analysis [54] or strain typing after re-inoculation in 'reporter' mouse lines ([35, 175], see also Sect. 3.3). Similar observations have been obtained with other prions. Thus, sporadic and genetic CJD isolates can be experimentally propagated in bank voles, a newly discovered rodent TSE model, with a low transmission barrier despite the divergence between human and vole PrP sequences [140]. Moreover the incubation time observed on primary inoculation to voles was similar to that in transgenic mice overexpressing human $\operatorname{PrP}[5,22]$. Parallel transmission of the same CJD cases to inbred mice was inefficient [140], consistent with earlier transmis- sion data $[35,78,91]$. In contrast, transmission to mice of variant CJD cases of the same PrP genotype was efficient [35], whereas transmission to bank voles was inefficient (U. Agrimi, personal communication). Another noticeable example is the ability of certain scrapie isolates to transmit readily to transgenic mice expressing bovine PrP, without significant reduction of incubation time on further passaging ([176] and our unpublished data), thus indicating a low transmission barrier. There is now a general consensus that both the strain and the $\operatorname{PrP}$ sequence of the recipient host are primary determinants of the species barrier [56]. A majority of the so-called species barriers could actually be seen as strain barriers [176].

\subsection{Influence of the route of infection}

The route of infection constitutes another critical factor that can modify the magnitude of the transmission barrier. In most experimental setups aiming to assess the potential of transmission to another species, infections are performed by intracranial route. 'Natural', mostly oral, routes of infection are usually much less efficient than intracranial inoculation [109]. For instance the infectious titer of the 139A mouse scrapie strain (Tab. I) is $10^{5}$ lower 
when infection is performed by the intragastric instead of the intracerebral route [107]. The ability of peripherally-injected prions to replicate in extraneural, permissive tissues such as Peyer's patches in the intestinal tract, spleen, tonsils, appendix or lymph nodes may also be critical in determining their ability to persist in the host before spreading to the peripheral then central nervous system (for reviews $[109,126])$. The infectivity levels in lymphoid tissues greatly vary depending on the prion agent or strain type [12]. Some scrapie strains, the CWD and vCJD agents are able to replicate in such tissues [2, 178, 200] whereas accumulation of BSE prions in cattle is only evidenced in the terminal ileum, in experimental infection yet not in natural cases [191]. Intriguingly, a prion agent can become lymphotropic upon interspecies transmission, as seen for BSE in sheep [75] or vCJD in humans [200]. In sheep, the host $\operatorname{PrP}^{C}$ sequence is also known to influence prion distribution within lymphoid tissues [101]. In addition, prions can spread directly from the enteric to the central nervous system without the need to replicate extraneurally (for review [15]). Such a pathway appears to be associated with a decreased attack rate. The relative importance of all these factors, which have been relatively well studied during within-species transmission, is less known in interspecies transmission.

\section{EVOLUTION OF PRION STRAINS ON INTERSPECIES TRANSMISSION}

The cross-species transmission of TSE agents can lead to different outcomes (summarised in Fig. 2), which may vary according to the strain involved and in an essentially unpredictable manner in the present state of knowledge.

\section{1. 'Absolute' species barrier}

A host may be refractory to infection by prions from another species. The best example is the rabbit, which is resistant to intracranial challenge with TSE agents from several species, including sheep scrapie, murine prions, human CJD and kuru [78] and BSE. This has suggested an intrinsic resistance of the host

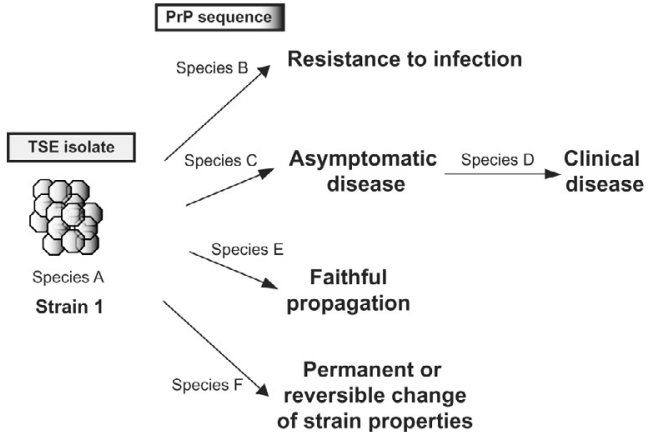

Figure 2. Interspecies transmission of prions. Main outcomes observed following experimental crossspecies transmission. To be pointed out, infection with a different strain from species A may lead to a similar or quite different outcome.

to disease rather than a strain effect. To determine whether this was intrinsically linked to the rabbit $\mathrm{PrP}^{\mathrm{C}}$ sequence, Vorberg et al. generated rabbit-mouse PrP chimaeras and analyzed which regions conferred resistance to mouse prion infection in otherwise permissive cell lines. They concluded that different domains of the rabbit $\operatorname{PrP}^{\mathrm{C}}$ sequence were likely to be involved [199]. We introduced the ovine $\operatorname{Pr} P$ gene (VRQ allele) by transgenesis in the rabbit. Upon infection with sheep scrapie, rabbits rapidly develop a typical TSE disease accompanied by accumulation of $\mathrm{PrP}^{\mathrm{Sc}}$ in the brain ${ }^{2}$. These findings lend support for a preponderant role of the $\operatorname{PrP}^{\mathrm{C}}$ sequence over other host factors in the resistance of the rabbit to various TSE agents. Two other 'absolute' species barriers in mice have recently been broken. Expression of mink PrP [206] and cervid PrP $[30,82,113,117,134,188]$ in transgenic mice render them susceptible to TME and CWD, respectively. It is noteworthy that the use of transgenic mice overexpressing mouse $\mathrm{PrP}^{\mathrm{C}}$ also allowed the propagation of the CWD agent [179].

\footnotetext{
${ }^{2}$ Sarradin P., Transgenic models to study human and animal diseases: prion diseases, 2nd International Meeting on Rabbit Biotechnology (2007).
} 


\subsection{Subclinical disease, long term persistence and 'dead ends'}

The success of an intra- and inter-species transmission is gauged routinely by the appearance of neurological signs, which precede the fatal outcome. Does, however, the lack of clinical symptoms imply an absolute species barrier? Such a situation, observed for instance after inoculation of hamster prions (263K strain, Tab. I) to inbred mice [106], has been revisited by the groups of Chesebro and Collinge [92, 158, 159]. First, they showed that substantial levels of hamster-like prion-infectivity persisted in mouse brains for months, since they were able to retransmit disease in recipient hamsters but not in mice. This was unexpected since residual infectivity was shown to be rapidly degraded when replication is impaired in animals such as $\operatorname{PrP}$ knock-out mice [39], an observation they reproduced with the $263 \mathrm{~K}$ strain [158]. The long-term 'retention' of $263 \mathrm{~K}$ was therefore dependant on $\operatorname{PrP}^{\mathrm{C}}$ expression in the mouse brain, suggesting some kind of interaction, either stabilization or low level conversion, between mouse $\mathrm{PrP}^{\mathrm{C}}$ and hamster $\mathrm{PrP}^{\mathrm{Sc}}$. Subsequently, an active replication of prions apparently took place, leading to inconsistent detection of mouse $\mathrm{PrP}^{\mathrm{res}}$. This accompanied the appearance of novel strain components, which on further passage were either pathogenic for mice but not anymore for hamsters or still virulent for hamsters but less for mice, although distinct from the parental $263 \mathrm{~K}$ strain.

The long-term 'persistence' of inoculated TSE agents in the brains of infected individuals might not be infrequent in situations of apparently impaired cross-species transmission. As mentioned above (see Sect. 2.2), Nonno et al. found that transmission of human CJD cases to conventional mice was poor, based on the absence of clinical signs. While a few inoculated mice accumulated $\mathrm{PrP}^{\mathrm{res}}$ and had spongiform lesions, even a second passage in mice failed to transmit the disease, suggesting no adaptation. Nonetheless parallel reinoculation into bank voles induced disease as efficiently as CJD directly, and with a similar phenotype [140]. In experiments aimed at modeling the potential susceptibility of hu- mans homozygous for valine at codon 129 to the BSE agent, transgenic mice expressing this allele were inoculated with natural isolates [201]. None of the mice developed a clinical disease nor accumulated $\mathrm{PrP}^{\mathrm{res}}$ in their brain. Some diffuse deposits were inconsistently observed by immunohistochemistry. Secondary passages were performed on the same transgenic line and on wild-type FVB mice. While neither clinical sign nor PrPres were evidenced in transgenic mice, suggesting a 'dead end' on this genetic background, a disease was still observed in some FVB mice, and this within a 'short' delay that was not compatible with the simple persistence of the original inoculum on primary passage.

These findings lead to the conclusion that (i) the force of a species barrier must not simply be assessed on a clinical basis; (ii) subclinical diseases must be distinguished from a slowly processing disease, whose incubation period would exceed the normal lifespan but be more visible on secondary transmission; (iii) an interaction between heterologous PrP species may occur and trigger conversion below the threshold of PrPres detectable by conventional methods; (iv) new strain types with unprecedented properties could emerge; (v) these new prions may not be pathogenic for the host, but still for a third species or the donor one. Collectively these findings have obvious public health implications. From a fundamental viewpoint, they question the nature of the neurotoxic/pathologic $\mathrm{PrP}^{\mathrm{Sc}}$ species.

\subsection{Conservation of strain phenotype}

A conservation of the strain phenotype is generally observed upon experimental transmission to transgenic mice expressing a $\operatorname{PrP}$ gene homologous to that present in the infecting source (see Sect. 2.1). Not only the $\mathrm{PrP}^{\mathrm{res}}$ molecular pattern $[5,54,119,175]$ but also some clinical aspects (scratching, hyperexcitability etc.), pathological lesions such as plaques or, interestingly, the presence or absence of tropism for the lymphoid tissue [5, $22,119]$ may be faithfully preserved in these recipient hosts.

Prions may also maintain phenotypic traits upon transmission to host with heterologous 
$\operatorname{PrP}^{\mathrm{C}}$ sequence (either transgenic mice or animals from other species), including preservation of specific $\mathrm{PrP}^{\mathrm{res}}$ molecular signature [54] or histopathological features [60, 179]. Reinoculation to the parental host (or transgenic mice expressing the corresponding $\mathrm{PrP}$ sequence) and demonstration that the original phenotype is restored may also argue for a conservation of the strain properties. For instance, the mouse scrapie strain Chandler/139A could be rescued in mice despite intermediate transmission into rats ([108], see Sect. 3.4.1). Often complicating the interpretation of such findings, however, is the possibility that the strain phenotype actually changed, but reverted upon propagation in the original host.

Experimental transmission to a common, 'reporter' species has highlighted the remarkable ability of the BSE agent to retain its biological properties after intermediate passage in a range of different hosts with distinct $\mathrm{PrP}^{\mathrm{C}}$ sequences. In initial studies, transmission of various sources of infected cattle to a panel of inbred mice expressing the a or $b$ mouse $\mathrm{PrP}$ allele (see section 3.4.1) suggested that cattle have been infected by a single strain since incubation periods and distribution of spongiosis in the brain were uniform in each genotype, unlike that seen with scrapie or CJD isolates $[31,35,83]$. The two agents propagated on $\mathrm{a}$ and $\mathrm{b}$ genotypes were termed $301 \mathrm{C}$ and 301V, respectively (Tab. I). Strikingly, 301C and $301 \mathrm{~V}$ were invariably obtained irrespectively of the species infected by the BSE agent, either accidentally (cats, exotic ruminants, humans) or experimentally (sheep, goats, pigs, macaques) [31, 35, 118]. It should be kept in mind, however, that the BSE agent underwent a single passage through the intermediate host. It remains unclear whether a more thorough adaptation to these species would lead uniformly to a conservation of the strain phenotype.

Surprisingly enough, a divergent evolution of the BSE agent has been reported following transmission to various lines of inbred mice, all carrying the Prnp- $a$ allele [5]. Careful phenotype comparison confirmed the presence of two distinct mouse strains, one resembling the Chandler strain, the other the mouse BSE strain [5, 125]. This was an important observation since it suggests that other loci than PrP might influence not only the susceptibility $[124,136]$ but also the strain evolution. Puzzlingly, however, these results have not been reproduced in another study using a similar panel of inbred mice and different BSE isolates [45].

More recently, Espinosa et al. revisited BSE agent stability after passage through sheep species [73]. The transmission features were compared with cattle BSE in mice transgenic for bovine PrP [48]. While the molecular and pathological phenotypes were undistinguishable, sheep-passaged BSE induced a significantly shorter disease on the first but also subsequent passages, thus excluding different infectivity levels in cattle and sheep brains as a possible explanation. Such an increased 'virulence' of the agent questions the definition of a prion strain or at minima calls for refined methods to distinguish some phenotypic changes that may currently be overlooked (see Sect. 4.1). In addition, these data raise the possibility that BSE prions may gain virulence by passage in another species, including human primates [118].

\subsection{Emergence of a new strain}

The possible emergence of a new strain upon experimental transmission to a foreign species is a phenomenon that has been described long before PrP was discovered. The first example is the observation that experimental transmission of a pool of scrapieinfected sheep brains (SSBP/1) to goats resulted in two clinical disease phenotypes either a 'scratching' or 'drowsy' syndrome that were conserved on subpassage [145, 146]. The question arises of whether distinct strain components pre-existed in the original pool and found clinical manifestation in goats, or whether a variant TSE agent emerged upon confrontation to a foreign PrP sequence. This is a recurrent dilemma in experimental interspecies transmission of prions. 


\subsubsection{Lessons from studies in rodent models}

Bessen and Marsh identified two distinct disease phenotypes after the serial transmission of the Stetsonville isolate of transmissible mink encephalopathy (TME) to hamsters. They were termed Hyper and Drowsy (HY and DY, respectively) because either hyperexcitability or drowsiness predominates at clinical stage [23]. In addition, both incubation times and brain $\mathrm{PrP}^{\mathrm{res}}$ molecular patterns differed in hamsters, indicating that two strains were isolated (Tab. I, [25]). DY but not HY retained pathogenicity for mink through at least four passages in hamsters, suggesting the possibility that it was the major if not the sole mink pathogen component in the original source [24]. When the Stetsonville isolate was biologically cloned by three transmissions at endpoint dilutions in mink, so as to isolate a single strain from a potential mixture before transmission to hamsters, both $\mathrm{HY}$ and DY PrP $^{\text {res }}$ patterns were again detected on first passage and both strains could be stably propagated on serial passage [11]. At the molecular level, this suggests that mink $\mathrm{PrP}^{\mathrm{Sc}}$ has the ability to convert hamster $\operatorname{PrP}^{\mathrm{C}}$ into more than one stable hamster $\mathrm{PrP}^{\mathrm{Sc}}$ conformation. Interestingly, an interference/competition effect between the different strain components appeared to occur and to influence the appearance of one or the other phenotype [13].

The relevance of biological cloning in an attempt to distinguish between selection from a 'strain mixture' or emergence of a 'mutant' is further underlined by the transmission of the 'Chandler' mouse strain (also termed 139A) to rats, which itself resulted from the serial adaptation (three passages) of the 'drowsy goat' source to mice (Tab. I). In initial experiments, Pattison and Jones adapted it to rats for five passages. Back into mice, the strain had lost its Chandler phenotype [147]. Kimberlin et al. performed a similar experiment but the Chandler strain (31 passages) had been previously cloned by three serial passages in mice at limiting dilutions [108]. After three interspecies passages into rats and three more back into mice, a strain indistinguishable from Chandler was reisolated. Also to be noted, the parallel transmission of the Chandler strain to hamsters before repassage to mice led to the isolation of the 139-H/M strain with properties different from Chandler/139A, indicating that the strain change was dependent upon the intermediate host.

Similar cross-transmission studies of mouse-adapted scrapie prions (see Tab. I) have been performed between lines of inbred mice that express the $a$ or $b \operatorname{PrP}$ allele. These alleles encode proteins that differ by two amino acids at positions 108 and 189. Prn-a mice are Leu-108 / Thr-189 and Prn- $b$ mice are Phe-108 / Val-189 (formerly designated as s7 and p7, respectively). 139A, which has been isolated in Prn-a mice has unchanged properties in Prn-b mice, whether or not biologically cloned. On the contrary, the mouse strain 22C (also isolated in Prn-a mice) gives rise to another type, termed $22 \mathrm{H}$ on transmission to Prn-b mice. If the strain has been previously cloned however, it stays $22 \mathrm{C}$. This suggests that $22 \mathrm{H}$ is a likely, minor component of uncloned 22C. Finally, both uncloned and cloned 22A strain that have been isolated in $P r n-b$ mice may give rise to $22 \mathrm{~F}$ in Prn- $a$ mice, suggesting that the $22 \mathrm{~F}$ type is a mutant. Thus minimal amino acid differences between the PrP sequence of the host and donor may be sufficient to influence the emergence of minor strain components upon cross-transmissions.

\subsubsection{New strains can emerge from classical and atypical BSE agents}

The above-mentioned phenomena have found a recent echo with cattle TSE (Fig. 3). Experimental transmission of BSE isolates to transgenic mice expressing methionine at $\mathrm{PrP}$ codon 129 led unexpectedly to the apparition of an alternative, sporadic CJD-like phenotype in a proportion of mice [5]. This observation has worrying implications in terms of public health since it raised the possibility that humans infected with BSE might be categorized as sporadic CJD patients. Modeling human-tohuman transmission of vCJD, we inoculated another line of humanized transgenic mice with vCJD cases. A proportion of mice was found to propagate a sporadic CJD-like strain in their brains [22], a divergent evolution that 
A
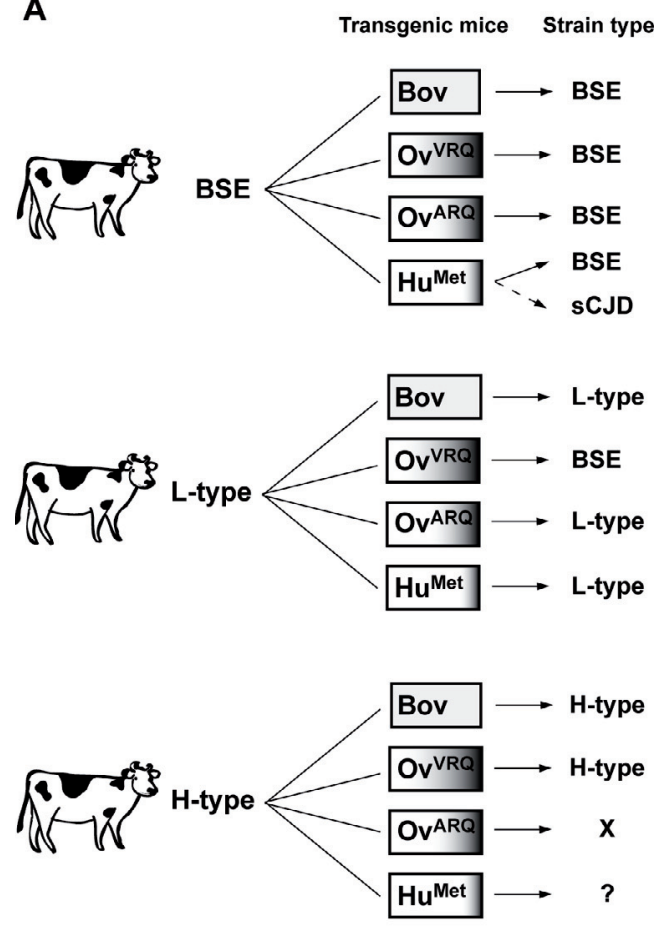

B

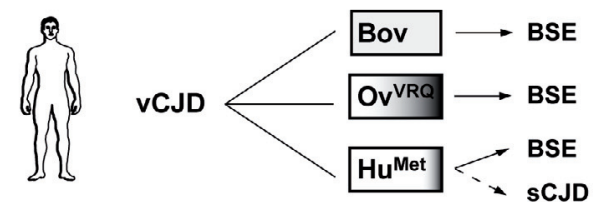

Figure 3. Stability and evolution of cattle and vCJD prion strains. (A) Three distinct forms of bovine spongiform encephalopathy have been identified through $\mathrm{PrP}^{\mathrm{res}}$ molecular typing on brain tissue. They are associated with zoonotic ('classical') BSE cases and uncommon ('atypical') BSE cases (Ltype or H-type). These agents maintain distinct properties on serial passage in mice transgenic for bovine PrP (Bov) supporting the existence of at least three distinct prion strains in cattle [21, 42, 45]. Their potential of interspecies transmission has been assessed with transgenic mice expressing sheep VRQ $\left(\mathrm{Ov}^{\mathrm{VRQ}}\right)$ or ARQ allele $\left(\mathrm{Ov}^{\mathrm{ARQ}}\right)$ or human (MM allele, $\mathrm{Hu}^{\mathrm{Met}}$ ) PrP. Properties of the BSE agent may be altered on passage in humanized mice, leading to the emergence of a sporadic CJDlike (sCJD) strain [5]. L-type is also transmissible to humanized mice $[21,114]$. Whereas the H-type is faithfully propagated in $\operatorname{PrP}^{\mathrm{VRQ}}$ transgenic mice [20], a new strain, converging to BSE appears on transmission of L-type BSE to these mice [21]. A different situation was observed in $\operatorname{PrP}^{\mathrm{ARQ}}$ mice: the H-type was not transmissible and the L-type agent was faithfully propagated [8]. (B) Variant CJD (vCJD) exhibits strain-specific traits undistinguishable from BSE on transmission to bovine and ovine $\left(\mathrm{PrP}^{\mathrm{VRQ}}\right)$ transgenic mice, further comforting their etiological link [20, 175]. Variant CJD agent may also occasionally undergo a strain shift on transmission to humanized mice, leading to sporadic CJD-like strain in a proportion of mice [22].

slightly lower molecular size and a different glycopattern, and a tendency to form amyloid plaques in cattle brain ([27, 42, 47] and Sect. 5.2). Inoculation to mice transgenic for bovine PrP demonstrated the infectious nature of such cases and confirmed their unique but distinctive strain phenotype as compared to BSE (Fig. 3 and [21, 42, 45]). Primary transmission of an Italian BSE-L case (termed BASE, for bovine amyloidogenic spongiform encephalopathy) to a panel of inbred mouse lines did not induce any clinical disease, nor $\mathrm{PrP}^{\mathrm{res}}$ accumulation. On secondary transmission however, a proportion of mice developed a disease with phenotypic traits undistinguishable from the BSE agent that has followed the same transmission history [45]. Intriguingly, 
transmission of BASE and three French L-type isolates to mice expressing ovine PrP (VRQ allele) also produced a shift towards a strain biochemically and neuropathologically undistinguishable from BSE, in this case from the primary passage on [21]. These findings raise the question of a possible relationship between the BSE-L and zoonotic BSE agents, an aspect that will be discussed below (see Sect. 5.2).

It is noteworthy that a similar convergence phenomenon had already been observed with the cloned mouse strain ME7 (Tab. I). ME7 can be transmitted to hamsters leading to ME7-H. However back into mouse, the original ME7 phenotype is rescued [108, 174]. Yet intermediate passage through a transgenic host chimeric for mouse and hamster PrP (tg $\mathrm{MH} 2 \mathrm{M}$ ) before further transmission to the hamster produced a strain faster than ME7$\mathrm{H}$, and undistinguishable of the $263 \mathrm{~K}$ hamster strain. However, back into mice, this $263 \mathrm{~K}$ like reverted to ME7 [174].

To summarize, the passaging of prions into foreign species can lead to either conservation of strain phenotype or emergence of a variant strain with unprecedented properties.

\section{INSIGHT INTO THE MOLECULAR DETERMINISM OF THE INTERSPECIES BARRIER}

\subsection{Molecular conformation of $\operatorname{PrP}^{\mathrm{Sc}}$ during cross-species transmission}

Even though precise information on the $\mathrm{PrP}^{\mathrm{Sc}}$ three-dimensional structure is lacking, a wealth of experimental data suggests that prion strains are associated with distinct $\mathrm{PrP}^{\mathrm{Sc}}$ conformations (Tab. II).

Documenting a conformational change associated with an interspecies transmission, however, is a more difficult task. Peretz et al. have shown that the $\operatorname{PrP}^{\mathrm{Sc}}$ conformational stability in the presence of chaotropic agents such as guanidine hydrochloride or urea greatly varies among prion strains [148]. Using this method, they have monitored variations in protein stability associated with either an abrupt change or a faithful conservation of the strain phenotype [149]. The hamster strain Sc237 (Tab. I) exhibits a substantial species barrier on transmission to mice expressing mouse/hamster chimeric PrP (tgMH2M). Reinoculation of hamsters with serially passaged tgMH2M-Sc237 yielded a strain with properties different from Sc237, consistent with the emergence of a new strain. This was accompanied by significant changes in relative conformational stability. The $[\mathrm{Gdn}]_{1 / 2}$ value of hamster Sc237 decreased from $\sim 1.8 \mathrm{M}$ to $\sim 1.1 \mathrm{M}$ upon transmission to $\operatorname{tgMH} 2 \mathrm{M}$ mice, and this irreversibly, as shown by repassage into hamsters. In sharp contrast, the DY hamster strain, which could be passaged and reisolated in hamsters without any phenotypic change, showed a stable $[\mathrm{Gdn}]_{1 / 2}$ value $(\sim 1.0 \mathrm{M})$. It is noteworthy that Western blotting failed to demonstrate a change in $\mathrm{PrP}^{\text {res }}$ molecular profile of either strain. These data thus established a relationship between species barrier, change in $\mathrm{PrP}^{\mathrm{Sc}}$ conformation and emergence of a new strain.

Very recently, luminescent conjugated polymers (polythiophene acetic acid polythiophene methyl imidazole), which exhibit conformation-dependant emission spectra on TSE-infected brain sections, have been able to detect changes in $\mathrm{PrP}^{\mathrm{Sc}}$ conformations that were invisible by Western blot, during serial adaptation of CWD to mouse transgenic for mouse PrP [180]. Spectral changes were noted over four passages of CWD, suggesting a gradual, host-constrained change in the supramolecular arrangement of $\mathrm{PrP}^{\mathrm{Sc}}$ deposits within the brain.

\subsection{Cell-free systems}

In further attempts to clarify the molecular mechanisms underlying the conversion of $\mathrm{PrP}^{\mathrm{C}}$ into $\mathrm{PrP}^{\mathrm{Sc}}$, cell-free systems have been developed, an approach pioneered by Caughey et al. In its simpler principle, it consists to incubate purified, metabolicallylabeled $\mathrm{PrP}^{\mathrm{C}}$ with semi-purified $\mathrm{PrP}^{\mathrm{Sc}}$. Conversion efficacy is monitored by apparition of labeled, protease-resistant $\mathrm{PrP}^{\mathrm{Sc}}$ after 1-3 days incubation at $37{ }^{\circ} \mathrm{C}[50,111]$. In a recent work, such a converting activity was reported to be dependent upon the size of $\operatorname{PrP}^{\mathrm{Sc}}$ aggregates used as seeds [182]. These studies supported the view that $\mathrm{PrP}^{\mathrm{Sc}}$ formation occurs 
through a nucleated polymerization process rather than a heterodimer mechanism. They also provided an interesting insight into the strain and species barrier phenomena. First, in homotypic conversion reactions, the conformation of newly converted $\operatorname{PrP}^{\mathrm{C}}$ appears to be imposed by that of the $\operatorname{PrP}^{\mathrm{Sc}}$ parental molecule. Thus, HY and DY $\mathrm{PrP}^{\mathrm{Sc}}$ are able to transmit their specific protein cleavage characteristics to neo-converted hamster $\operatorname{PrP}^{\mathrm{C}}$ [26]. Similarly, PrP ${ }^{\text {res }}$-specific glycoform ratio may be conserved [198]. Second, interactions between $\mathrm{PrP}^{\mathrm{C}}$ and $\mathrm{PrP}^{\mathrm{Sc}}$ proteins are sequence specific and parallel to some extent those observed in interspecies transmission in vivo. Thus conversion of mouse $\mathrm{PrP}^{\mathrm{C}}$ by hamster $\operatorname{PrP}^{\mathrm{Sc}}(263 \mathrm{~K})$ was inefficient [112]. At a time where in vivo data were limited, the cellfree conversion approach has suggested that the potential susceptibility of humans to TSE agents such as BSE, scrapie or CWD might be relatively low $[162,161]$. The pronounced influence of sheep PrP genotypes on susceptibility to the scrapie agent was also modeled with some accuracy in vitro [29].

Kinetically, the cell-free conversion was described as a two-step process $[65,95]$. In the first step, $\operatorname{PrP}^{\mathrm{C}}$ binds to $\mathrm{PrP}^{\mathrm{Sc}}$ and becomes sedimentable but remains protease-sensitive. Importantly, this binding step seems highly sequence-specific, i.e. not intrinsically related to the sticky properties of $\operatorname{PrP}^{\mathrm{Sc}}[65,166]$. Moreover heterologous binding can be as efficient as homologous binding, whether or not conversion does occur [96, 166]. The second step is the conversion sensu stricto and it follows at a slower pace. $\mathrm{PrP}^{\mathrm{C}}$ undergoes a conformational change and acquires a protease-resistant state [43, 65, 95, 166]. This step necessitates further intermolecular interactions between $\operatorname{PrP}^{\mathrm{C}}$ and $\operatorname{PrP}^{\mathrm{Sc}}$. Horiuchi et al. demonstrated that heterologous $\operatorname{PrP}$ molecules were able to interfere with the conversion of homologous $\operatorname{PrP}^{\mathrm{C}}$ [96], possibly accounting for the interference phenomenon described in cell cultures or in mice expressing more than one PrP allele $[39,152,156,190]$. The observed interference effect appeared to involve the conversion rather than the binding step [96].
Altogether, the above studies led to propose several scenarios that might occur at the molecular level when a TSE agent is transmitted to other species. As an extreme case, the initial binding of $\operatorname{PrP}^{\mathrm{C}}$ to the heterologous $\mathrm{PrP}^{\mathrm{Sc}}$ present in the incoming TSE agent may not be allowed, probably because of structural incompatibility, leading to a complete resistance to infection, or 'absolute' species barrier (Sect. 3.1). Otherwise, binding is allowed and further conversion may take place. The force of the species barriers may therefore be determined more by the pace at which the conversion step occurs than by the initial binding. Such a molecular mechanism could explain the long-term, subclinical, $\mathrm{PrP}^{\mathrm{C}}$ dependant persistence of hamster prions in mice (Sect. 3.2).

In earlier experiments of cell-free conversion, the emergence of $\mathrm{PrP}^{\mathrm{Sc}}$ species with properties distinct of the seeding $\mathrm{PrP}^{\mathrm{Sc}}$ has been reported but apparently not reproduced $[96,112]$. The probability to observe a diverging molecular evolution using this technique may be limited because it is likely to involve mainly 'single hit' conversion, in which newly produced $\mathrm{PrP}^{\mathrm{Sc}}$ molecules are not converting other $\mathrm{PrP}^{\mathrm{C}}$ molecules. The possibility to amplify 'indefinitely' $\mathrm{PrP}^{\mathrm{Sc}}$ in cell-free conditions, recently achieved by a technique termed protein-misfolding cyclic amplification (PMCA), may soon provide further insight into the molecular determinisms involved $[49,167]$.

\subsection{Studies with recombinant $\operatorname{PrP}$}

Studies involving fibrils made of bacterially expressed PrP have provided another glimpse of the strain/species barrier concept. They are based on the properties of recombinant PrP to polymerize into amyloid fibrils either spontaneously or upon addition of a small amount of pre-formed fibrils. Such a seeding effect is a feature of the nucleation-dependant polymerization process (for reviews see [14, $139,187]$ ). Surewicz et al. elegantly modeled 'prion strain' diversity in a simple system consisting of seeded fibrilization of soluble monomeric prion protein variants ( $\mathrm{PrP} 23-$ 144). They generated amyloid fibrils from a 
A

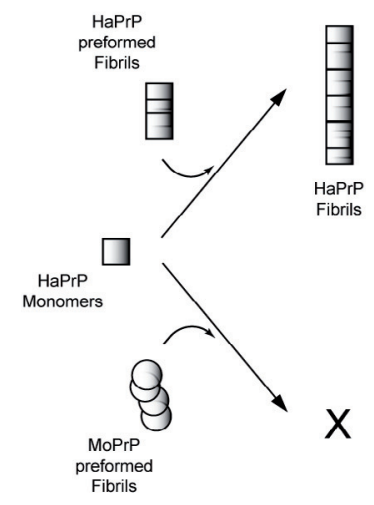

B

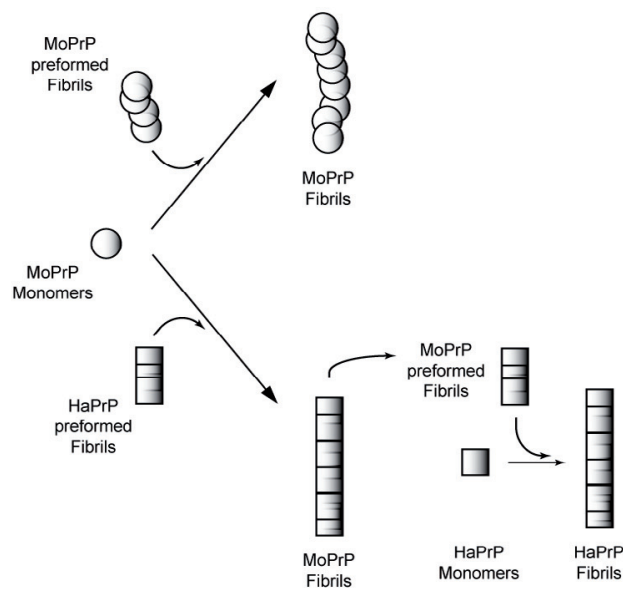

Figure 4. Strain and cross-species transmission as modeled with PrP fibrils. (A) Monomers of recombinant, truncated hamster $\operatorname{PrP}(\mathrm{Ha})$ rapidly polymerized into amyloid fibrils upon addition of a small amount of preformed hamster fibrils as a seed (upper panel). Hamster PrP monomers cannot be converted by mouse PrP seeds (lower panel). (B) On the contrary, mouse PrP monomers can be converted by either mouse (upper panel) or hamster (lower panel) PrP seeds. The conformation of the neosynthesised fibrils is similar to that of the parental hamster seed and differs from that obtained on mouse-to-mouse conversion. This newly formed mouse polymer is now able to trigger fibrilization of hamster PrP monomers (lower panel, right). Overall these experiments suggest that the conformation of the PrP seed controls the cross-species seeding efficiency [103, 196]. truncated portion of mouse, human or hamster recombinant PrP, which were morphologically and spectroscopically distinct $[103,196]$. They next examined the cross-seeding capabilities of these fibrils (Fig. 4). While hamster monomers could not be converted by mouse fibril seeds, the opposite reaction was possible. These hamster-generated mouse fibrils were now able to trigger polymerization of the hamster monomers. Moreover they appeared to have adopted the secondary structure and the fibril architecture of the parental amyloid hamster seed, which differed from the second generation of mouse fibrils generated by preseeding of mouse monomers with mouse fibrils [103]. These authors also showed the critical influence of point mutations on the seeding barrier [103, 196]. Positions 138 and 139 were particularly important as they differ in amino acid composition among the three species studied. Species-specific point mutation profoundly affected the seeding specificity of PrP23-144. This was accompanied by a change in the conformation of the amyloid, with mutant fibrils adopting that of PrP corresponding to different species. Thus human variant $\operatorname{PrP}$ with isoleucine to methionine mutation at positions 138 and 139, as in the hamster, mimicked the seeding specificity of hamster fibrils and adopted a hamster-like fibril conformation.

These experiments suggest therefore that (i) the seeding properties are encoded in amyloid fibril conformation; (ii) some type of seeds might be able to interact with heterologous monomers because they are within the spectrum of allowed conformations. This requires the normal protein to be conformationally 'adaptable' to the conformation of the amyloid seed; (iii) the portfolio of conformations the monomer can adopt upon polymerization is dictated by its amino acid sequence. Thus the fibril conformation and PrP sequence are intrinsically related. These experiments have led to the concept that prion strains and PrPsequence barriers may therefore be opposite sides of a single coin [187]. Conceptually similar conformational inheritance was also supported by studies performed on the structurally unrelated protein Sup35, the infectious 
determinant of the yeast prion state [Psi+] (for review [53]). However, these findings may not be entirely relevant in vivo since truncated, unglycosylated and anchorless forms of recombinant $\mathrm{PrP}$ were used in these experiments. Of note, similar polymerisation experiments using full-length recombinant mouse and hamster PrP failed to reproduce these data. There was no specificity in cross-seeding fibrilization of mouse and hamster and the fibrils formed were a hybrid of both polymers [128]. Further studies may thus be needed to learn to which extent such mechanisms do control the transmissibility of prions across species.

\subsection{The conformational selection hypothesis}

Taking into account the advances of the knowledge on both yeast [53, 189, 193] and mammalian prions [55], a unified model has emerged that integrates the prion strain and species barrier concept within the proteinonly context (comprehensively reviewed by [57]). In this model, both prion strains and species barriers are basically manifestations of the same phenomenon, namely the capacity of a single protein to misfold into multiple, aggregated conformations. Each mammalian species would have a portfolio of possible $\mathrm{PrP}^{\mathrm{Sc}}$ conformations (Fig. 5), essentially determined by the $\mathrm{PrP}^{\mathrm{Sc}}$ conformation in the infecting inoculum and the conformational constraints imposed by the host primary PrP structure. Thus an amino acid change in the $\mathrm{PrP}^{\mathrm{C}}$ protein sequence can modulate this spectrum. In turn, a change in $\mathrm{PrP}^{\mathrm{Sc}}$ conformation associated with interspecies transmission might modify the host species range and/or the strain phenotypic traits of the agent. The force of the species barrier will be determined by the degree of overlap between the favored conformations for host and donor $\mathrm{PrP}^{\mathrm{Sc}}$. In other words, heterologous transmission in which the incoming $\mathrm{PrP}^{\mathrm{Sc}}$ has a conformation within the portfolio of conformations allowed by the host will result in a low species barrier. If conformation is incompatible, the transmission barrier will be high and only be crossed by emergence of a variant showing better structural compatibility (see below).
For a given species, the extent of the $\mathrm{PrP}^{\mathrm{Sc}}$ portfolio could be larger than that observable in natural disease or upon experimental infection. It is indeed possible that more $\mathrm{PrP}^{\mathrm{Sc}}$ types exist but are eliminated for instability, rate of replication, or other parameters relevant to the fitness of the infectious agent [57]. The strain convergence phenomenon observed during inter-species transmission experiments ([21, 45, 174], Sect. 3.3.2) lends support for a relatively finite rather than a continuous portfolio of favored conformations [120]. Recently it has been shown that infectious prions could be spontaneously generated using PMCA from healthy brains unseeded with prions [66]. It would be of interest to see to which extent the spectrum of artificially created $\mathrm{PrP}^{\mathrm{Sc}}$ conformations will overlap that of the natural one.

Although one dominant $\mathrm{PrP}^{\mathrm{Sc}}$ conformation is commonly detected in the infecting inoculum, other may be present, in variable proportions. This diversity may reflect the presence of more than one strain in the inoculum [106] or the intrinsic variety of physicochemical states of $\mathrm{PrP}^{\mathrm{Sc}}$ in an infecting source, even if it is assumed to be clonal. Minor conformational states might be present, increasing the probability of overlap between incoming $\mathrm{PrP}^{\mathrm{Sc}}$ and $\mathrm{PrP}^{\mathrm{Sc}}$ types preferred by host $\mathrm{PrP}^{\mathrm{C}}$. Thus, on confrontation with a new $\operatorname{PrP}^{\mathrm{C}}$ sequence, a subdominant $\mathrm{PrP}^{\mathrm{Sc}}$ subpopulation might preferentially polymerise, resulting in a strain shift. Alternatively, multiple $\mathrm{PrP}^{\mathrm{Sc}}$ types might be produced de novo during the intermolecular interplay with heterologous $\operatorname{PrP}^{\mathrm{C}}$ molecules. Whatever the mechanism(s) involved, i.e. either pre-existing or de novo produced conformational heterogeneity, the adaptation may be gradual, possibly requiring iterated transmissions into the new host before a strain -not necessary clonal- with stable phenotypic traits is established.

Might other factors modulate the efficacy of cross-species transmission? The cellular environment is likely to play a key role. The host machinery that usually degrades misfolded proteins [210] may eliminate most of the newly converted proteins. Cellular chaperonelike activities might also be involved in the conversion process, as shown in vitro [65, 


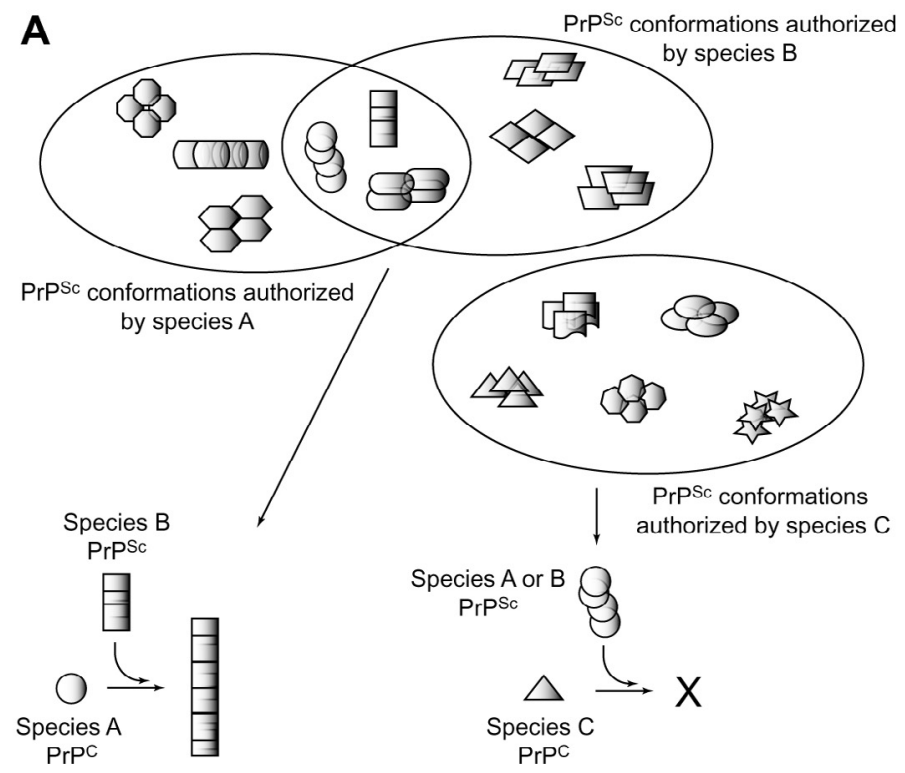

B
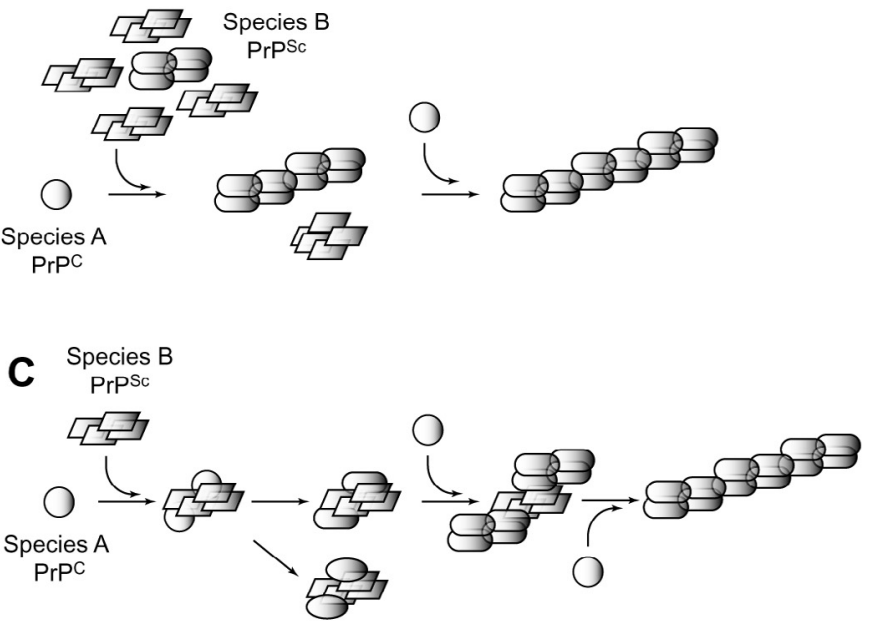

Figure 5. Conformational hypothesis and strain evolution on interspecies transmission. (A) Diagram illustrating the spectrum of conformations that $\operatorname{PrP}^{\mathrm{C}}$ of species $\mathrm{A}, \mathrm{B}$ or $\mathrm{C}$ can adopt in the $\mathrm{PrP}^{\mathrm{Sc}}$ state and the potential overlap. Transmission of species $\mathrm{B} \mathrm{PrP}^{\mathrm{Sc}}$ to species A may occur because species $\mathrm{A} \operatorname{PrP}^{\mathrm{C}}$ can adopt a conformation compatible with the infecting strain. The transmission barrier would therefore be relatively low (left). On the contrary, conformations of $\mathrm{PrP}^{\mathrm{Sc}}$ molecules of species $\mathrm{C}$ are not compatible with those allowed in species A or species B. The transmission barrier between these species will be high (right). (B) Compatible conformations between species A and B may be selected because the species B infecting inoculum is composed of heterogeneous $\mathrm{PrP}^{\mathrm{Sc}}$ conformations. In the example shown, a minor component of the inoculum is preferentially replicated, resulting in a strain phenotype shift. (C) Alternatively, multiple $\mathrm{PrP}^{\mathrm{Sc}}$ conformations may be produced de novo during molecular interactions between species $\mathrm{A} \operatorname{PrP}^{\mathrm{C}}$ and the conformationally incompatible $\mathrm{PrP}^{\mathrm{Sc}}$ of species $\mathrm{B}$ thus increasing the probability to generate a conformation allowed by species A. 
207]. The question arises of whether the spectrum of $\mathrm{PrP}^{\mathrm{Sc}}$ conformations allowed by $\mathrm{PrP}^{\mathrm{C}}$ might differ to a certain extent among the tissues or brain regions. $\operatorname{PrP}^{\mathrm{C}}$ isoforms or glycoforms exhibit a regional heterogeneity in the brain $[19,63,64]$. It is tempting to suggest that this might modulate the capacity of a prion to cross the species barrier. In turn, it may specify the strain-specific regional distribution of $\mathrm{PrP}^{\mathrm{Sc}}$ in the brain [90].

\section{STRAIN DIVERSITY AND POTENTIAL OF INTERSPECIES TRANSMISSION OF ANIMAL PRIONS}

\subsection{TSE in sheep and goats}

Scrapie is the best known of the TSE in animals. The disease was discovered more than two centuries ago in the United-Kingdom. Scrapie is used as a generic term to designate TSE in sheep and goats, but the number of prion strain(s) actually involved has remained elusive so far. Polymorphism in the PrP gene strongly influences the development of the disease (see Sect. 2.1). The pronounced resistance of animals homozygous for the ARR allele has been the basis of genetic selection of breeds resistant to disease in a few European countries such as France, the United-Kingdom and the Netherlands. A novel, 'atypical' form of scrapie has been discovered more recently in sheep and goat European flocks through active surveillance programs based on the rapid biochemical detection of $\mathrm{PrP}^{\text {res }}$ in the animal brain. The abnormal PrP associated with these atypical cases is characterized by a lower resistance to protease digestion as compared to classical scrapie. Furthermore, confirmatory neuropathological methods were often inconclusive [18]. Atypical scrapie has been diagnosed in sheep carrying various PrP genotypes, including those homozygous for ARR $[40,137,141]$. Its prevalence approaches that of classical scrapie in Europe ${ }^{3}$.

\footnotetext{
${ }^{3}$ Seac sheep subgroup position statement [on line] (2006) http://www.seac.gov.uk/pdf/positionstatement-sheep-subgroup.pdf [consulted 23/03/2008]
}

\subsubsection{Strain diversity in the natural host}

So far, three distinct strains have been identified in the sheep and two of them stably passaged in the natural host: SSBP/1 (originating from the scrapie Cheviot sheep pool brain, [68]), CH1641 (isolated from a UK Cheviot sheep in the 1970s', [74]) and atypical scrapie [183].

Analyses of brain $\mathrm{PrP}^{\mathrm{res}}$ from natural scrapie cases revealed that scrapie molecular features are not uniform, consistent with the existence of distinct strains. Three major types of $\mathrm{PrP}^{\mathrm{res}}$ profiles have been identified, with unglycosylated forms (see Fig. 1B) migrating at $\sim 21 \mathrm{kDa}$ as in $\mathrm{SSBP} / 1$, at $\sim 19 \mathrm{kDa}$ as in CH1641 or BSE-like isolates or showing the additional presence of truncated fragments at $\sim 10-12 \mathrm{kDa}$ when visible in atypical isolates [94, 121, 160, 211]. A fourth type with unglycosylated form migrating at $16-17 \mathrm{kDa}$ has also been mentioned by some authors [94, 211].

\subsubsection{Strain typing in the mouse}

Appreciation of potential scrapie diversity has relied, for the past three decades, on serial experimental transmission of natural isolates to a panel of inbred mouse lines with Prn- $a$ or $b$ genotypes (for review [37]). The strains are classified by the range of incubations they produce within the genotype used for stabilization but also in the other and in the F1 progeny. The distribution and severity of spongiform degeneration in standardized brain regions is then established in each genotype. In reviewing the published history of these transmission data, initiated by Dickinson et al. and pursued by Bruce et al., it appears that the considerable strain variations described at a point (up to 20 strains, $[32,70])$ might finally be restricted to a varying combination of three distinct strains, as far as UK field scrapie cases are concerned (20 isolates studied): ME7 and 87A in Prn$a$ mice, and $87 \mathrm{~V}$ in Prn- $b$ mice (Tab. I, [33, $36,37]$ ). More recent transmission of $10 \mathrm{UK}$ scrapie cases identified again ME7 and possibly a new strain, termed 221C (Tab. I, [36]). The ME7 strain was first isolated in mice by serial passage of Suffolk sheep natural scrapie 
spleen onto C57BL/6 mice [212]. This strain has been shown to be pathogenic back into sheep and goats after two passages in mice [213]. The relationship of the mouse-adapted strains with TSE agents naturally occurring in sheep is not clear. They may include new strains with properties different from the original ones that have emerged as a consequence of the transmission barrier (see Sect. 3.3). The origin of the diversity within the initial panel of 20 mouse-adapted strains is unclear. Amongst these, 14 were distinct, 4 were not stable [33]. Amongst these 14, 12 have for origin SSBP/1 (a pool of sheep brains) or goatpassaged SSBP/1 (the 'drowsy' goat source) and subsequent selection on Prn-a or $b$ mice (Tab. I, [33, 37, 36, 165]). The last two resulted from BSE transmission to Prn- $a$ and $b$ mice as mentioned above in Section 3.3 [35].

It is also important to notice that a substantial proportion of scrapie isolates failed to transmit to mice, in particular the scrapie sources from sheep homozygous for the ARQ allele [36, 37, 97]. So far it has been impossible to derive mouse TSE agents from these sources. This includes the CH1641 strain, passaged on this sheep genetic background [74]. Conventional inbred mouse lines are also refractory to isolates from atypical cases [38, 119].

The potential scrapie strain diversity in the USA (five isolates studied, [46]) and Japan (eight sources, [97]) has also been examined by similar methods. Diversified phenotypic traits were observed after transmission to mice, suggesting the existence of distinct strains. The potential overlap between American and European field scrapie strains has not been examined rigorously. Finally, the relationship between goat and sheep scrapie strains is currently unknown.

\subsubsection{Assessment of scrapie strain diversity with transgenic mouse models}

The use of a combination of transgenic mouse lines expressing ovine (or caprine) Prnp genes may permit to get a more comprehensive view of TSE agent diversity in small ruminants because of a lower transmission bar- rier and potentially a lower selection pressure compared to conventional mice (see Sect. 2.1). As a striking example, transmission of atypical scrapie cases has been achieved in 'ovinized' transgenic mice, which overexpress the VRQ allele [119]. The atypical biochemical signature, i.e. the presence of an additional, low molecular band migrating at $\sim 10-12 \mathrm{kDa}$ in Western blots and its particular sensitivity to proteinase $\mathrm{K}$ digestion was conserved in the recipient mice. Moreover, little or no shortening of the incubation time was observed on further passage for a number of isolates. PrP genotypes of the donor animals (sheep and goat) did not notably influence the incubation time either. Further analyses demonstrated that all the atypical cases transmitted so far involve a unique strain, closely related if not identical to that present in Nor98 cases that were discovered earlier on in Norway ([17, 18, 119] and our unpublished data). Notably, this strain exhibits fairly high infectious titre, including in ARR-homozygous sheep [119]. Although the aetiology of atypical scrapie is still speculative, a sporadic, spontaneous origin is currently favored [17, 138]. Additional investigations would be needed to determine whether sporadic cases in small ruminants might involve TSE agents distinct from Nor98.

The strain diversity of classical scrapie is also currently being explored in ovine $\mathrm{PrP}^{\mathrm{VRQ}}$ transgenic mice. The transmission of $\sim 80$ isolates throughout Europe has permitted to classify them into four distinct classes, all being notably different from BSE passaged in sheep or goats $([20,21,119,197]$ and our unpublished data), either experimentally or naturally [71]. The molecular behaviours of sheep scrapie isolates in ovine transgenic mice expressing another PrP allele (ARQ mice, [60]) were also variable, suggesting the existence of distinct strains. Some exhibited features similar to $\mathrm{CH} 1641$ ( $\sim 19 \mathrm{kDa}$ PrP $^{\text {res }}$ signature). In other, $\sim 21 \mathrm{kDa}$ forms predominated and there was a mixture of both $[6,9]$. It is noteworthy that similar strain typing studies are currently being pursued with the newly developed bank vole model ([140] and U. Agrimi, R. Nonno, personal communication). 


\subsubsection{Potential of interspecies transmission of scrapie}

What is the state of knowledge about the cross-species potential of sheep scrapie, besides rodents? Cattle and mice transgenic for bovine PrP are susceptible to US or European scrapie isolates $([62,73,115,176]$ and our unpublished data). None of the disease phenotypes observed so far resemble BSE, not supporting the hypothesis that BSE could originate from a scrapie agent. Regarding the potential of scrapie to infect humans, no epidemiological link between scrapie and humans has been evidenced. Sporadic CJD incidence is roughly similar worldwide whether countries are highly infected or free of scrapie [116]. The recent discovery of atypical cases, which have been undetected for years $[38,70]$ and thus may be present in countries 'free' of scrapie but unnoticed because a very limited numbers of biochemical tests are performed, weakens this argument. Sheep scrapie can be intracranially transmitted to non human primates [78, 118]. In one report, the observed phenotype was intriguingly similar to sporadic CJD upon further transmission to inbred mice [118], which may simply reflect a strain convergence phenomenon. A more thorough examination of the cross-species potential of the scrapie agent taking into account the increased knowledge in terms of natural strain diversity and the availability of various human PrP transgenic mouse lines would be suitable.

\subsection{Cattle TSE}

\subsubsection{Diversity of TSE strains in cattle}

As reported in Section 3, there is good evidence to indicate that a unique major prion strain is responsible for the BSE epizooty. Thus far, it is the only known animal prion disease that has been transmitted to humans, leading to a variant form of CJD. A little more than 20 years after the first BSE cases were diagnosed in the United-Kingdom, the epizooty is under control in most European countries ${ }^{4}$.

\footnotetext{
${ }^{4}$ Number of reported cases of bovine spongiform encephalopathy (BSE) in farmed cattle worldwide (excluding the United Kingdom) [on line] (2008)
}

The large-scale testing of livestock nervous tissues for the presence of $\operatorname{PrP}^{\mathrm{Sc}}$ has been one of the measures taken to exclude BSE-infected animals from human food and thus limit the number of vCJD cases. This active and systematic surveillance has brought to light the existence of variant molecular signatures and thus potentially new strains, distinct from BSE. These have been detected in rare cases of aged cattle, a low prevalence consistent with the possibility of sporadic forms of TSE in cattle [28]. In addition to the L-type group already mentioned (see Sect. 3.3.2), which has been identified in France [28], Italy [47], Germany [42] and Poland [151], a second group termed $\mathrm{H}$-type has been found. Its $\mathrm{PrP}^{\text {res }}$ signature is characterized by protease-resistant fragments of an increased size and a different glycopattern as compared to BSE [27]. Cases have been found so far in France [28], Great Britain [192], Germany [42], the Netherlands [100], USA [164], Sweden [77] and Switzerland (in a zebu, [177]). Like L-type, H-type is transmissible to mice transgenic for bovine PrP, thus establishing its infectious nature [20]. These agents both maintain their original molecular phenotype in bovine PrP mice and are neuropathologically distinct from each other as well as from BSE (Fig. 3). L-type is more virulent than BSE than H-type in these mice. These data therefore demonstrate unambigously the existence of distinct TSE strains in cattle.

\subsubsection{Potential of interspecies transmission of atypical cattle TSE}

H-type was successfully transmitted to conventional [10] and ovine $\mathrm{PrP}^{\mathrm{VRQ}}$-expressing mice (Fig. 3, [20]). In PrP $\mathrm{PRQ}^{\mathrm{VR}}$ mice, the transmission barrier was lower than for BSE on primary passage. At variance with the L-type (see Sect. 3.3.2), the strain-specific features observed on primary and subsequent passages were clearly distinct from that of the BSE agent [20].

Interestingly, transmission of the three cattle TSE strains to $\operatorname{PrP}^{\mathrm{ARQ}}$ mice results in a markedly different outcome compared to

http://www.oie.int/eng/info/en_esbmonde.htm [consulted 23/03/2008]. 
PrP ${ }^{V R Q}$ mice (Fig. 3). Indeed, BSE propagates in $\mathrm{PrP}^{\mathrm{ARQ}}$ - mice without an obvious transmission barrier, the H-type is not transmissible and L-type isolates induce disease faster than BSE and retain their initial phenotype $[8,20$, $21,59]$. It remains to be clarified whether such a discrepant behaviour is indeed attributable to the PrP polymorphism at codon 136 , or to the different genetic backgrounds and/or $\operatorname{PrP}$ constructs in the $\operatorname{PrP}^{\mathrm{ARQ}}$ and $\operatorname{Pr} \mathrm{P}^{\mathrm{VRQ}}$ mouse lines [60]. Sheep homozygous for the ARQ allele are more susceptible to BSE than VRQ/VRQ sheep [98]. It will be of great interest to study the behavior and stability of $\mathrm{H}$ and L-type strains in experimentally infected sheep.

Finally, it is to note that, although more thorough strain phenotype examination will be necessary, L-type BSE exhibits a distinct molecular phenotype as compared to BSE on transmission to transgenic mice expressing human $\operatorname{PrP}[21,114]$. Worryingly, it seems to replicate faster than $\mathrm{BSE}$ in these mice [21]. The potential pathogenicity of the H-type agent for 'humanized' transgenic mice is currently unknown.

\subsubsection{Atypical BSE in cattle, the origin of epizootic BSE?}

Although the recycling of BSE-infected carcasses into meat and bone meals distributed to cattle has clearly been incriminated in the massive extension of the BSE epizooty, the origin of the BSE agent is still a mystery [7, 204]. BSE might have arose spontaneously in cattle, due to a somatic- or germ-line mutation of PrP. Cattle may also have been infected by prions from another species such as sheep, involving a strain change or not $[62,115]$. The observations (mentioned in Sect. 3.4.2) that the BSE-L agent has an intrinsic tendency to evolve towards a BSE-like agent upon crossspecies infection events points to the theoretical possibility of a multiple causative event, in which a prion sporadically present in cattle may have 'mutated' through passage on an intermediary host, such as a sheep. The relationship between the classical and L-type BSE agent needs to be clarified in future studies. A key question is whether or not the L-type de- rived agent will maintain its classical BSE-like strain phenotype once inoculated in transgenic mice for bovine PrP.

\subsection{Chronic wasting disease}

\subsubsection{Strain diversity in CWD?}

Chronic wasting disease (CWD) is a prion disease that affects both free-ranging and captive animals that are farmed for meat and hunting, such as mule deer, white-tailed deer, Rocky mountain elk and more recently moose (comprehensively reviewed in [181]). First discovered in Colorado in 1967, the disease has expanded geographically to a large part of North America, including Canada. Its origin is unknown but several aspects of CWD physiopathology are reminiscent of sheep scrapie. A methionine/leucine polymorphism at codon 132 (site corresponding to codon 129 in humans) of elk $\operatorname{Pr} P$ gene influences the susceptibility to CWD. Sick animals homozygous for Met at codon 132 are overrepresented [142], an effect reproduced in transgenic mice [82]. The disease can spread horizontally and the attack rate can be important in farmed cervids (up to 95\%). Some endemic pockets have been notified. Body fluids are infectious and saliva is suspected to favor the horizontal, particularly efficient, dissemination of the disease [132]. At variance with scrapie, the placenta is poorly infectious, suggesting that transmission from mother-to-lamb might be rather low [135]. The CWD agent has a pronounced tropism for lymphoid tissues and muscles are infectious [3, 178]. Thus CWD is today taken as seriously as BSE in Europe by health authorities. Of particular importance is to assess its potential of cross-species transmission for other farm animals potentially in contact with cervids (cattle, sheep), wild-life scavengers (raccons etc.) and humans, in particular hunters and venison meat eaters. It is essential in this respect to document any strain variation of CWD agents, a task that is complicated by the multiplicity of the affected species. The $\mathrm{PrP}^{\mathrm{res}}$ electropheretic profiles are relatively homogeneous among cervids, both in terms of molecular weights, around $21 \mathrm{kDa}$ for the unglycosylated species, and glycoform ratios [160, 209]. However a deeper comparison of 
the isolates through conformation-dependant immunoassay (CDI, Tab. II) identified two distinct populations, one in the elk, and the other in deer [170]. Recently, an alternative $19 \mathrm{kDa}$ pattern has also been observed in diseased elk with leucine at codon 132 [142]. This was associated with a longer incubation than for animals carrying the 132-methionine allele. Whether this finding reflects different strains or simply the propagation of the same strain on two distinct PrP genotypes is unclear. However the marked resistance to CWD of mice transgenic for elk prion protein with L132 allele [82] might argue for the presence of another strain. Over the last few years, several transgenic mouse lines have been developed that express either elk or mule-deer PrP [30, 113, 117, 188], with polymorphisms at codon 132 or 96 [82, 134]. It should be noted that mice expressing glycine at $\operatorname{PrP}$ residue 96 were fairly susceptible to oral infection by the CWD agent [194], or when the transgene was not overexpressed [134]. Although most transmission data are consistent with the existence of one single strain [188], there has been variations in either incubation periods, which were conserved on subpassage, or neuropathological features among the transmitted isolates [30, 82, 117], suggesting straindependent variations. LaFauci et al. proposed in particular that strains might differ among the mule deer and elk [117], as previously evidenced with $\mathrm{PrP}^{\mathrm{Sc}}$ conformation studies [170]. The emergence of two strains has been observed on serial adaptation of CWD inocula to hamsters [163]. One resembled $263 \mathrm{~K}$ while the other had much longer incubation periods (up to 500 days) and distinct neuropathological patterns. It is possible that these strains diverged from a unique one on passage to an intermediate species, as described for the TME agent transmitted to hamsters (see Sect. 3.3.1).

\subsubsection{Potential of interspecies transmission of CWD}

The potential of cervid prions to infect other species has been assessed in various experimental setups. In vitro cell free conversion of human and bovine $\mathrm{PrP}^{\mathrm{C}}$ by $\mathrm{CWD} \mathrm{PrP}^{\mathrm{Sc}}$ was poor, suggesting a substantial molecu- lar barrier that would limit susceptibility of these species to disease $[162,163]$. These results were further confirmed in transgenic mice expressing bovine and human PrP (Met allele) and extended to ovine $\operatorname{PrP}^{\mathrm{VRQ}}$ mice. All were refractory to intracranial inoculation $[113,188]$. Calves are susceptible to intracranial injection of deer CWD (11/12 infected). The phenotype observed, notably the absence of spongiform changes, makes the disease distinguishable from other TSE in cattle [88]. Eight Suffolk lambs showing various genotypes - four ARQ/ARR, three ARQ/ARQ, one ARQ/VRQ at codons 136, 154, and 171, respectively - showed intermediate susceptibility [87]. Only one (ARQ/VRQ) had a clinical disease, and another a subclinical one (ARQ/ARQ), suggesting a role of the host genotype as for scrapie. Last but not least, squirrel monkeys were permissive to CWD following intracerebral inoculation [130]. The time to terminal disease ( $\sim 30$ months) was within the range of that reported for sporadic CJD or kuru (11-48 months). Such studies suggesting a possible susceptibility of humans to CWD prions must be interpreted with caution. In particular, oral or peripheral routes of exposure would constitute a more "natural' one. Thus studies placing cattle in close contact to diseased cervids have resulted in no case of natural transmission [81]. Finally, scavenging animals, such as raccoons are refractory to exposure to high concentration of cervid prions [85], whereas they showed susceptibility to TME or scrapie $[85,86]$.

\section{CONCLUSIONS AND FUTURE OUTLOOK}

The strain diversity in natural prion diseases is a well-established fact. The current view is still imprecise and is likely to improve with the wider utilisation of genetically engineered mice, the continuation of large-scale testing in animals and refined methods of molecular analyses. The information gathered from experimental transmission points to selection pressure during PrP sequence crossing as a potential driving force in the evolution of prions. However, to which extent such an evolution 
occurs in a natural context remains to be determined. Several lines of evidence suggest that the natural strain diversity may be finite. It will be of interest to see if the use of PMCA technology will challenge this point owing to its recent breakthroughs.

At the molecular level, much remains to be learned about the physical relationship between infectivity and misfolded PrP particles, and to which extent it varies according to the PrP sequence and/or prion strain. There are also examples of infectivity in the absence of detectable $\mathrm{PrP}^{\mathrm{res}}$ or presence of $\mathrm{PrP}^{\text {res }}$ without obvious transmissibility. Further biophysical studies are clearly needed to determine $\mathrm{PrP}^{\mathrm{Sc}}$ structure and define at high resolution the conformational differences within and between prion strains. This is of importance because conformational polymorphism is common to several amyloid pathologies and may modulate their severity [150].

Our current ability to estimate the transmission barrier relies essentially on the use of bioassays in transgenic mouse models because other experimental approaches using large animals are not practical and obviously impossible in humans. The fact that two major determinants of the species barrier are experimentally confronted in these experiments constitutes a critical advantage. Because experimental transmissions are generally forced (i.e. high doses and non-natural infection routes), caution must however be exerted when extrapolating these data. On the other hand, an absolute resistance to infection constitutes robust information in terms of risk assessment. In the near future, the PMCA technology could provide an alternative predictive tool, although the recent reporting of de novo creation of 'spontaneous' prions may put a damper on this. A substantial gain in resolving molecular differences among prion strains may help to decipher the molecular basis of the transmission barrier. This scientific challenge might pave the way for refined tools to estimate the risk of interspecies transmissibility of prions and the potential to generate new strains, which currently raises serious public health issues.
Acknowledgements. We thank Claire Laude for drawings in graphics. This work was supported by grants from the Neuroprion European Network of Excellence.

\section{REFERENCES}

[1] Aguzzi A., Heikenwalder M., Polymenidou M., Insights into prion strains and neurotoxicity, Nat Rev Mol. Cell Biol. (2007) 8:552-561.

[2] Andreoletti O., Berthon P., Marc D., Sarradin P., Grosclaude J., van Keulen L., et al., Early accumulation of $\mathrm{PrP}^{\mathrm{Sc}}$ in gut-associated lymphoid and nervous tissues of susceptible sheep from a Romanov flock with natural scrapie, J. Gen. Virol. (2000) 81:31153126.

[3] Angers R.C., Browning S.R., Seward T.S., Sigurdson C.J., Miller M.W., Hoover E.A., et al., Prions in skeletal muscles of deer with chronic wasting disease, Science (2006) 311:1117.

[4] Anonymous, Fourth case of transfusion-associated vCJD infection in the United Kingdom, Euro. Surveill. (2007) 12:E070118.4.

[5] Asante E.A., Linehan J.M., Desbruslais M., Joiner S., Gowland I., Wood A.L., et al., BSE prions propagate as either variant CJD-like or sporadic CJD-like prion strains in transgenic mice expressing human prion protein, EMBO J. (2002) 21:6358-6366.

[6] Baron T., Crozet C., Biacabe A.G., Philippe S., Verchere J., Bencsik A., et al., Molecular analysis of the protease-resistant prion protein in scrapie and bovine spongiform encephalopathy transmitted to ovine transgenic and wild-type mice, J. Virol. (2004) 78:6243-6251.

[7] Baron T., Biacabe A.G., Origin of bovine spongiform encephalopathy, Lancet (2006) 367:297-298.

[8] Baron T., Bencsik A., Biacabe A.G., Morignat E., Bessen R.A., Phenotypic similarity of transmissible mink encephalopathy in cattle and 1-type bovine spongiform encephalopathy in a mouse model, Emerging Infect. Dis. (2007) 13:1887-1894.

[9] Baron T., Biacabe A.G., Molecular behaviors of "CH1641-like" sheep scrapie isolates in ovine transgenic mice (TgOvPrP4), J. Virol. (2007) 81:7230 7237.

[10] Baron T.G., Biacabe A.G., Bencsik A., Langeveld J.P., Transmission of new bovine prion to mice, Emerging Infect. Dis. (2006) 12:1125-1128.

[11] Bartz J.C., Bessen R.A., McKenzie D., Marsh R.F., Aiken J.M., Adaptation and selection of prion protein strain conformations following interspecies transmission of transmissible mink encephalopathy, J. Virol. (2000) 74:5542-5547.

[12] Bartz J.C., Dejoia C., Tucker T., Kincaid A.E., Bessen R.A., Extraneural prion neuroinvasion without lymphoreticular system infection, J. Virol. (2005) 79:11858-11863. 
[13] Bartz J.C., Kramer M.L., Sheehan M.H., Hutter J.A., Ayers J.I., Bessen R.A., et al., Prion interference is due to a reduction in strain-specific $\mathrm{PrP}^{\mathrm{Sc}}$ levels, $\mathrm{J}$. Virol. (2007) 81:689-697.

[14] Baskakov I.V., Breydo L., Converting the prion protein: what makes the protein infectious, Biochim. Biophys. Acta (2007) 1772:692-703.

[15] Beekes M., McBride P.A., The spread of prions through the body in naturally acquired transmissible spongiform encephalopathies, FEBS J. (2007) 274:588-605.

[16] Belt P.B., Muileman I.H., Schreuder B.E., Bosde Ruijter J., Gielkens A.L., Smits M.A., Identification of five allelic variants of the sheep PrP gene and their association with natural scrapie, J. Gen. Virol. (1995) 76:509-517.

[17] Benestad S.L., Sarradin P., Thu B., Schönheit J., Tranulis M.A., Bratberg B., Cases of scrapie with unusual features in Norway and designation of a new type, Nor98, Vet. Rec. (2003) 153:202-208.

[18] Benestad S.L., Arsac J.N., Goldmann W., Nöremark M., Atypical/Nor98 scrapie: properties of the agent, genetics, and epidemiology, Vet. Res. (2008) 39:19.

[19] Béringue V., Mallinson G., Kaisar M., Tayebi M., Sattar Z., Jackson G., et al., Regional heterogeneity of cellular prion protein isoforms in the mouse brain, Brain (2003) 126:2065-2073.

[20] Béringue V., Bencsik A., Le Dur A., Reine F., Lai T.L., Chenais N., et al., Isolation from cattle of a prion strain distinct from that causing bovine spongiform encephalopathy, PLoS Pathog. (2006) 2:e112.

[21] Béringue V., Andréoletti O., Le Dur A., Essalmani R., Vilotte J.L., Lacroux C., et al., A bovine prion acquires an epidemic bovine spongiform encephalopathy strain-like phenotype on interspecies transmission, J. Neurosci. (2007) 27:6965-6971.

[22] Béringue V., Le Dur A., Tixador P., Reine F., Lepourry L., Perret-Liaudet A., et al., Prominent and persistent extraneural infection in human PrP transgenic mice infected with variant CJD, PLoS ONE (2008) 3:e1419.

[23] Bessen R.A., Marsh R.F., Biochemical and physical properties of the prion protein from two strains of the transmissible mink encephalopathy agent, J. Virol. (1992) 66:2096-2101.

[24] Bessen R.A., Marsh R.F., Identification of two biologically distinct strains of transmissible mink encephalopathy in hamsters, J. Gen. Virol. (1992) 73:329-334.

[25] Bessen R.A., Marsh R.F., Distinct PrP properties suggest the molecular basis of strain variation in transmissible mink encephalopathy, J. Virol. (1994) 68:7859-7868.

[26] Bessen R.A., Kocisko D.A., Raymond G.J., Nandan S., Lansbury P.T., Caughey B., Non-genetic propagation of strain-specific properties of scrapie prion protein, Nature (1995) 375:698-700.

[27] Biacabe A.G., Laplanche J.L., Ryder S., Baron T., Distinct molecular phenotypes in bovine prion diseases, EMBO Rep. (2004) 5:110-115.

[28] Biacabe A.G., Morignat E., Vulin J., Calavas D., Atypical bovine spongiform encephalopathies, france, 2001-2007, Emerging Infect. Dis. (2008) 14:298-300.

[29] Bossers A., Belt P., Raymond G.J., Caughey B., de Vries R., Smits M.A., Scrapie susceptibility-linked polymorphisms modulate the in vitro conversion of sheep prion protein to protease-resistant forms, Proc. Natl. Acad. Sci. USA (1997) 94:4931-4936.

[30] Browning S.R., Mason G.L., Seward T., Green M., Eliason G.A., Mathiason C., et al., Transmission of prions from mule deer and elk with chronic wasting disease to transgenic mice expressing cervid PrP, J. Virol. (2004) 78:13345-13350.

[31] Bruce M., Chree A., McConnell I., Foster J., Pearson G., Fraser H., Transmission of bovine spongiform encephalopathy and scrapie to mice: strain variation and the species barrier, Philos. Trans. R. Soc. Lond. B Biol. Sci. (1994) 343:405-411.

[32] Bruce M.E., Dickinson A.G., Biological evidence that scrapie agent has an independent genome, J. Gen. Virol. (1987) 68:79-89.

[33] Bruce M.E., Scrapie strain variation and mutation, Br. Med. Bull. (1993) 49:822-838.

[34] Bruce M.E., McBride P.A., Jeffrey M., Scott J.R., PrP in pathology and pathogenesis in scrapie-infected mice, Mol. Neurobiol. (1994) 8:105-112.

[35] Bruce M.E., Will R.G., Ironside J.W., McConnell I., Drummond D., Suttie A., et al., Transmissions to mice indicate that 'new variant' CJD is caused by the BSE agent, Nature (1997) 389:498-501.

[36] Bruce M.E., Boyle A., Cousens S., McConnell I., Foster J., Goldmann W., et al., Strain characterization of natural sheep scrapie and comparison with BSE, J. Gen. Virol. (2002) 83:695-704.

[37] Bruce M.E., TSE strain variation, Br. Med. Bull. (2003) 66:99-108.

[38] Bruce M.E., Nonno R., Foster J., Goldmann W., Di Bari M., Esposito E., et al., Nor98-like sheep scrapie in the United Kingdom in 1989, Vet. Rec. (2007) 160:665-666.

[39] Büeler H., Aguzzi A., Sailer A., Greiner R.A., Autenried P., Aguet M., et al., Mice devoid of PrP are resistant to scrapie, Cell (1993) 73:1339-1347.

[40] Buschmann A., Biacabe A.G., Ziegler U., Bencsik A., Madec J.Y., Erhardt G., et al., Atypical scrapie cases in Germany and France are identified by discrepant reaction patterns in BSE rapid tests, J. Virol. Methods (2004) 117:27-36. 
[41] Buschmann A., Groschup M.H., Highly bovine spongiform encephalopathy-sensitive transgenic mice confirm the essential restriction of infectivity to the nervous system in clinically diseased cattle, J. Infect. Dis. (2005) 192:934-942.

[42] Buschmann A., Gretzschel A., Biacabe A.G., Schiebel K., Corona C., Hoffmann C., et al., Atypical BSE in Germany-proof of transmissibility and biochemical characterization, Vet. Microbiol. (2006) 117:103-116.

[43] Callahan M.A., Xiong L., Caughey B., Reversibility of scrapie-associated prion protein aggregation, J. Biol. Chem. (2001) 276:28022-28028.

[44] Cancellotti E., Barron R.M., Bishop M.T., Hart P., Wiseman F., Manson J.C., The role of host PrP in transmissible spongiform encephalopathies, Biochim. Biophys. Acta (2007) 1772:673-680.

[45] Capobianco R., Casalone C., Suardi S., Mangieri M., Miccolo C., Limido L., et al., Conversion of the BASE prion strain into the BSE strain: the origin of BSE?, PLoS Pathog. (2007) 3:e31.

[46] Carp R.I., Callahan S.M., Variation in the characteristics of 10 mouse-passaged scrapie lines derived from five scrapie-positive sheep, J. Gen. Virol. (1991) 72:293-298.

[47] Casalone C., Zanusso G., Acutis P., Ferrari S., Capucci L., Tagliavini F., et al., Identification of a second bovine amyloidotic spongiform encephalopathy: molecular similarities with sporadic Creutzfeldt-Jakob disease, Proc. Natl. Acad. Sci. USA (2004) 101:30653070 .

[48] Castilla J., Gutiérrez Adán A., Brun A., Pintado B., Ramìrez M.A., Parra B., et al, Early detection of $\mathrm{PrP}^{\mathrm{res}}$ in BSE-infected bovine PrP transgenic mice, Arch. Virol. (2003) 148:677-691.

[49] Castilla J., Saá P., Hetz C., Soto C., In vitro generation of infectious scrapie prions, Cell (2005) 121:195-206.

[50] Caughey B., Kocisko D.A., Raymond G.J., Lansbury P.T. Jr., Aggregates of scrapie-associated prion protein induce the cell-free conversion of protease-sensitive prion protein to the proteaseresistant state, Chem. Biol. (1995) 2:807-817.

[51] Caughey B.W., Dong A., Bhat K.S., Ernst D., Hayes S.F., Caughey W.S., Secondary structure analysis of the scrapie-associated protein PrP 27-30 in water by infrared spectroscopy, Biochemistry (1991) 30:7672-7680.

[52] Chandler R.L., Fisher J., Experimental transmission of scrapie to rats, Lancet (1963) 2:1165.

[53] Chien P., Weissman J.S., DePace A.H., Emerging principles of conformation-based prion inheritance, Annu. Rev. Biochem. (2004) 73:617-656.

[54] Collinge J., Sidle K.C., Meads J., Ironside J., Hill A.F., Molecular analysis of prion strain variation and the aetiology of 'new variant' CJD, Nature (1996) 383:685-690.

[55] Collinge J., Variant Creutzfeldt-Jakob disease, Lancet (1999) 354:317-323.

[56] Collinge J., Prion diseases of humans and animals: their causes and molecular basis, Annu. Rev. Neurosci. (2001) 24:519-550.

[57] Collinge J., Clarke A.R., A general model of prion strains and their pathogenicity, Science (2007) 318:930-936.

[58] Cronier S., Beringue V., Bellon A., Peyrin J.M., Laude H., Prion strain- and species-dependent effects of antiprion molecules in primary neuronal cultures, J. Virol. (2007) 81:13794-13800.

[59] Crozet C., Bencsik A., Flamant F., Lezmi S., Samarut J., Baron T., Florid plaques in ovine PrP transgenic mice infected with an experimental ovine BSE, EMBO Rep. (2001) 2:952-956.

[60] Crozet C., Flamant F., Bencsik A., Aubert D., Samarut J., Baron T., Efficient transmission of two different sheep scrapie isolates in transgenic mice expressing the ovine PrP gene, J. Virol. (2001) 75:53285334.

[61] Cuillé J., Chelle P.L., La tremblante du mouton est bien inoculable, C. R. Acad. Sci. Paris (1938) 206:7879.

[62] Cutlip R.C., Miller J.M., Lehmkuhl H.D., Second passage of a US scrapie agent in cattle, J. Comp. Pathol. (1997) 117:271-275.

[63] DeArmond S.J., Sánchez H., Yehiely F., Qiu Y., Ninchak-Casey A., Daggett V.,et al., Selective neuronal targeting in prion disease, Neuron (1997) 19:1337-1348.

[64] DeArmond S.J., Qiu Y., Sànchez H., Spilman P.R., Ninchak-Casey A., Alonso D., et al., PrPc glycoform heterogeneity as a function of brain region: implications for selective targeting of neurons by prion strains, J. Neuropathol. Exp. Neurol. (1999) 58:1000 1009 .

[65] DebBurman S.K., Raymond G.J., Caughey B., Lindquist S., Chaperone-supervised conversion of prion protein to its protease-resistant form, Proc. Natl. Acad. Sci. USA (1997) 94:13938-13943.

[66] Deleault N.R., Harris B.T., Rees J.R., Supattapone S., Formation of native prions from minimal components in vitro, Proc. Natl. Acad. Sci. USA (2007) 104:9741-9746.

[67] Dell'Omo G., Vannoni E., Vyssotski A.L., Di Bari M.A., Nonno R., Agrimi U., et al., Early behavioural changes in mice infected with BSE and scrapie: automated home cage monitoring reveals prion strain differences, Eur. J. Neurosci. (2002) 16:735-742.

[68] Dickinson A.G., Stamp J.T., Renwick C.C., Rennie J.C., Some factors controlling the incidence 
of scrapie in Cheviot sheep injected with a Cheviotpassaged scrapie agent, J. Comp. Pathol. (1968) 78:313-321.

[69] Dickinson A.G., Meikle V.M., A comparison of some biological characteristics of the mouse-passaged scrapie agents, 22A and ME7, Genet. Res. (1969) 13:213-225.

[70] Dickinson A.G., Scrapie in sheep and goats, Front. Biol. (1976) 44:209-241.

[71] Eloit M., Adjou K., Coulpier M., Fontaine J.J., Hamel R., Lilin T.,.et al., BSE agent signatures in a goat, Vet. Rec. (2005) 156:523-524.

[72] Elsen J.M., Amigues Y., Schelcher F., Ducrocq V., Andreoletti O., Eychenne F., et al., Genetic susceptibility and transmission factors in scrapie: detailed analysis of an epidemic in a closed flock of Romanov, Arch. Virol. (1999) 144:431-445.

[73] Espinosa J.C., Andréoletti O., Castilla J., Herva M.E., Morales M., Alamillo E., et al., Sheep-passaged bovine spongiform encephalopathy agent exhibits altered pathobiological properties in bovine-PrP transgenic mice, J. Virol. (2007) 81:835-843.

[74] Foster J.D., Dickinson A.G., The unusual properties of CH1641, a sheep-passaged isolate of scrapie, Vet. Rec. (1988) 123:5-8.

[75] Foster J.D., Parnham D.W., Hunter N., Bruce M., Distribution of the prion protein in sheep terminally affected with BSE following experimental oral transmission, J. Gen. Virol. (2001) 82:2319-2326.

[76] Fraser H., Dickinson A.G., Scrapie in mice. Agent-strain differences in the distribution and intensity of grey matter vacuolation, J. Comp. Pathol. (1973) 83:29-40.

[77] Gavier-Widén D., Nöremark M., Langeveld J.P., Stack M., Biacabe A.G., Vulin J., et al., Bovine spongiform encephalopathy in Sweden: an H-type variant, J. Vet. Diagn. Invest. (2008) 20:2-10.

[78] Gibbs C.J., Jr., Gajdusek D.C., Experimental subacute spongiform virus encephalopathies in primates and other laboratory animals, Science (1973) 182:6768.

[79] Goldmann W., Hunter N., Foster J.D., Salbaum J.M., Beyreuther K., Hope J., Two alleles of a neural protein gene linked to scrapie in sheep, Proc. Natl. Acad. Sci. USA (1990) 87:2476-2480.

[80] Goldmann W., PrP genetics in ruminant transmissible spongiform encephalopathies, Vet. Res. (2008) 39:30.

[81] Gould D.H., Voss J.L., Miller M.W., Bachand A.M., Cummings B.A., Frank A.A., Survey of cattle in northeast Colorado for evidence of chronic wasting disease: geographical and high-risk targeted sample, J. Vet. Diagn. Invest. (2003) 15:274-277.

[82] Green K.M., Browning S.R., Seward T.S., Jewell J.E., Ross D.L., Green M.A., et al., The elk PRNP codon 132 polymorphism controls cervid and scrapie prion propagation, J. Gen. Virol. (2008) 89:598-608.

[83] Green R., Horrocks C., Wilkinson A., Hawkins S.A., Ryder S.J., Primary isolation of the bovine spongiform encephalopathy agent in mice: agent definition based on a review of 150 transmissions, J. Comp. Pathol. (2005) 132:117-131.

[84] Groschup M.H., Lacroux C., Buschmann A., Lühken G., Mathey J., Eiden M., et al., Classic scrapie in sheep with the ARR/ARR prion genotype in Germany and France, Emerging Infect. Dis. (2007) 13:1201-1207.

[85] Hamir A.N., Miller J.M., Cutlip R.C., Stack M.J., Chaplin M.J., Jenny A.L., et al., Experimental inoculation of scrapie and chronic wasting disease agents in raccoons (Procyon lotor), Vet. Rec. (2003) 153:121123.

[86] Hamir A.N., Miller J.M., O’Rourke K.I., Bartz J.C., Stack M.J., Chaplin M.J., Transmission of transmissible mink encephalopathy to raccoons (Procyon lotor) by intracerebral inoculation, J. Vet. Diagn. Invest. (2004) 16:57-63.

[87] Hamir A.N., Kunkle R.A., Cutlip R.C., Miller J.M., Williams E.S., Richt J.A., Transmission of chronic wasting disease of mule deer to Suffolk sheep following intracerebral inoculation, J. Vet. Diagn. Invest. (2006) 18:558-565.

[88] Hamir A.N., Kunkle R.A., Miller J.M., Bartz J.C., Richt J.A., First and second cattle passage of transmissible mink encephalopathy by intracerebral inoculation, Vet. Pathol. (2006) 43:118-126.

[89] Harper J.D., Lansbury P.T. Jr., Models of amyloid seeding in Alzheimer's disease and scrapie: mechanistic truths and physiological consequences of the time-dependent solubility of amyloid proteins, Annu. Rev. Biochem. (1997) 66:385-407.

[90] Hecker R., Taraboulos A., Scott M., Pan K.M., Yang S.L., Torchia M., et al., Replication of distinct scrapie prion isolates is region specific in brains of transgenic mice and hamsters, Genes Dev. (1992) 6:1213-1228.

[91] Hill A.F., Desbruslais M., Joiner S., Sidle K.C., Gowland I., Collinge J., et al., The same prion strain causes vCJD and BSE, Nature (1997) 389:448-450.

[92] Hill A.F., Joiner S., Linehan J., Desbruslais M., Lantos P.L., Collinge J., Species-barrier-independent prion replication in apparently resistant species, Proc. Natl. Acad. Sci. USA (2000) 97:10248-10253.

[93] Hilton D.A., Ghani A.C., Conyers L., Edwards P., McCardle L., Ritchie D., et al., Prevalence of lymphoreticular prion protein accumulation in UK tissue samples, J. Pathol. (2004) 203:733-739.

[94] Hope J., Wood S.C., Birkett C.R., Chong A., Bruce M.E., Cairns D., et al., Molecular analysis of ovine prion protein identifies similarities between 
BSE and an experimental isolate of natural scrapie, CH1641, J. Gen. Virol. (1999) 80:1-4.

[95] Horiuchi M., Caughey B., Specific binding of normal prion protein to the scrapie form via a localized domain initiates its conversion to the protease-resistant state, EMBO J. (1999) 18:3193-3203.

[96] Horiuchi M., Priola S.A., Chabry J., Caughey B., Interactions between heterologous forms of prion protein: binding, inhibition of conversion, and species barriers, Proc. Natl. Acad. Sci. USA (2000) 97:58365841 .

[97] Horiuchi M., Nemoto T., Ishiguro N., Furuoka H., Mohri S., Shinagawa M., Biological and biochemical characterization of sheep scrapie in Japan, J. Clin. Microbiol. (2002) 40:3421-3426.

[98] Houston F., Goldmann W., Chong A., Jeffrey M., González L., Foster J., et al., Prion diseases: BSE in sheep bred for resistance to infection, Nature (2003) 423:498.

[99] Ironside J.W., Bishop M.T., Connolly K., Hegazy D., Lowrie S., Le Grice M., et al., Variant CreutzfeldtJakob disease: prion protein genotype analysis of positive appendix tissue samples from a retrospective prevalence study, BMJ (2006) 332:1186-1188.

[100] Jacobs J.G., Langeveld J.P., Biacabe A.G., Acutis P.L., Polak M.P., Gavier-Widen D., et al., Molecular discrimination of atypical bovine spongiform encephalopathy strains from a geographical region spanning a wide area in Europe, J. Clin. Microbiol. (2007) 45:1821-1829.

[101] Jeffrey M., Begara-McGorum I., Clark S., Martin S., Clark J., Chaplin M., et al., Occurrence and distribution of infection-specific PrP in tissues of clinical scrapie cases and cull sheep from scrapie-affected farms in Shetland, J. Comp. Pathol. (2002) 127:264273.

[102] Jeffrey M., González L., Classical sheep transmissible spongiform encephalopathies: pathogenesis, pathological phenotypes and clinical disease, Neuropathol. Appl. Neurobiol. (2007) 33:373-394.

[103] Jones E.M., Surewicz W.K., Fibril conformation as the basis of species- and strain-dependent seeding specificity of mammalian prion amyloids, Cell (2005) 121:63-72.

[104] Kim Y.S., Carp R.I., Callahan S.M., Wisniewski H.M., Scrapie-induced obesity in mice, J. Infect. Dis. (1987) 156:402-405.

[105] Kimberlin R.H., Walker C., Characteristics of a short incubation model of scrapie in the golden hamster, J. Gen. Virol. (1977) 34:295-304.

[106] Kimberlin R.H., Walker C.A., Evidence that the transmission of one source of scrapie agent to hamsters involves separation of agent strains from a mixture, J. Gen. Virol. (1978) 39:487-496.
[107] Kimberlin R.H., Walker C.A., Pathogenesis of mouse scrapie: effect of route of inoculation on infectivity titres and dose-response curves, J. Comp. Pathol. (1978) 88:39-47.

[108] Kimberlin R.H., Cole S., Walker C.A., Temporary and permanent modifications to a single strain of mouse scrapie on transmission to rats and hamsters, J. Gen. Virol. (1987) 68:1875-1881.

[109] Kimberlin R.H., Walker C.A., Pathogenesis of experimental scrapie, Ciba Found. Symp. (1988) 135:37-62.

[110] Kimberlin R.H., Walker C.A., Fraser H., The genomic identity of different strains of mouse scrapie is expressed in hamsters and preserved on reisolation in mice, J. Gen. Virol. (1989) 70:2017-2025.

[111] Kocisko D.A., Come J.H., Priola S.A., Chesebro B., Raymond G.J., Lansbury P.T., Caughey B., Cellfree formation of protease-resistant prion protein, Nature (1994) 370:471-474.

[112] Kocisko D.A., Priola S.A., Raymond G.J., Chesebro B., Lansbury P.T. Jr., Caughey B., Species specificity in the cell-free conversion of prion protein to protease-resistant forms: a model for the scrapie species barrier, Proc. Natl. Acad. Sci. USA (1995) 92:3923-3927.

[113] Kong Q., Huang S., Zou W., Vanegas D., Wang M., Wu D., et al., Chronic wasting disease of elk: transmissibility to humans examined by transgenic mouse models, J. Neurosci. (2005) 25:7944-7949.

[114] Kong Q., Zheng M., Casalone C., Qing L., Huang S., Chakraborty B., et al., Evaluation of the human transmission risk of an atypical bovine spongiform encephalopathy prion strain, J. Virol. (2008) 82:3697-3701.

[115] Konold T., Lee Y.H., Stack M.J., Horrocks C., Green R.B., Chaplin M., et al., Different prion disease phenotypes result from inoculation of cattle with two temporally separated sources of sheep scrapie from Great Britain, BMC Vet. Res. (2006) 2:31.

[116] Ladogana A., Puopolo M., Croes E.A., Budka H., Jarius C., Collins S., et al., Mortality from Creutzfeldt-Jakob disease and related disorders in Europe, Australia, and Canada, Neurology (2005) 64:1586-1591.

[117] LaFauci G., Carp R.I., Meeker H.C., Ye X., Kim J.I., Natelli M., et al., Passage of chronic wasting disease prion into transgenic mice expressing Rocky Mountain elk (Cervus elaphus nelsoni) $\operatorname{PrP}^{\mathrm{C}}$, J. Gen. Virol. (2006) 87:3773-3780.

[118] Lasmézas C.I., Fournier J.G., Nouvel V., Boe H., Marcé D., Lamoury F., et al., Adaptation of the bovine spongiform encephalopathy agent to primates and comparison with Creutzfeldt-Jakob disease: implications for human health, Proc. Natl. Acad. Sci. USA (2001) 98:4142-4147. 
[119] Le Dur A., Béringue V., Andréoletti O., Reine F., Laï T.L., Baron T., et al., A newly identified type of scrapie agent can naturally infect sheep with resistant PrP genotypes, Proc. Natl. Acad. Sci. USA (2005) 102:16031-16036.

[120] Legname G., Nguyen H.O., Peretz D., Cohen F.E., DeArmond S.J., Prusiner S.B., Continuum of prion protein structures enciphers a multitude of prion isolate-specified phenotypes, Proc. Natl. Acad. Sci. USA (2006) 103:19105-19110.

[121] Lezmi S., Martin S., Simon S., Comoy E., Bencsik A., Deslys J.P., et al., Comparative molecular analysis of the abnormal prion protein in field scrapie cases and experimental bovine spongiform encephalopathy in sheep by use of Western blotting and immunohistochemical methods, J. Virol. (2004) 78:3654-3662.

[122] Liberski P.P., Bratosiewicz J., Walis A., Kordek R., Jeffrey M., Brown P., A special report I. Prion protein $(\mathrm{PrP})$-amyloid plaques in the transmissible spongiform encephalopathies, or prion diseases revisited, Folia Neuropathol. (2001) 39:217-235.

[123] Llewelyn C.A., Hewitt P.E., Knight R.S., Amar K., Cousens S., Mackenzie J., et al., Possible transmission of variant Creutzfeldt-Jakob disease by blood transfusion, Lancet (2004) 363:417-421.

[124] Lloyd S.E., Onwuazor O.N., Beck J.A., Mallinson G., Farrall M., Targonski P., et al., Identification of multiple quantitative trait loci linked to prion disease incubation period in mice, Proc. Natl. Acad. Sci. USA (2001) 98:6279-6283.

[125] Lloyd S.E., Linehan J.M., Desbruslais M., Joiner S., Buckell J., Brandner S., et al., Characterization of two distinct prion strains derived from bovine spongiform encephalopathy transmissions to inbred mice, J. Gen. Virol. (2004) 85:2471-2478.

[126] Mabbott N.A., MacPherson G.G., Prions and their lethal journey to the brain, Nat. Rev. Microbiol. (2006) 4:201-211.

[127] Mahal S.P., Baker C.A., Demczyk C.A., Smith E.W., Julius C., Weissmann C., Prion strain discrimination in cell culture: the cell panel assay, Proc. Natl. Acad. Sci. USA (2007) 104:20908-20913.

[128] Makarava N., Lee C.I., Ostapchenko V.G., Baskakov I.V., Highly promiscuous nature of prion polymerization, J. Biol. Chem. (2007) 282:3670436713 .

[129] Mallucci G., Collinge J., Rational targeting for prion therapeutics, Nat. Rev. Neurosci. (2005) 6:2334.

[130] Marsh R.F., Kincaid A.E., Bessen R.A., Bartz J.C., Interspecies transmission of chronic wasting disease prions to squirrel monkeys (Saimiri sciureus), J. Virol. (2005) 79:13794-13796.
[131] Masel J., Jansen V.A., Nowak M.A., Quantifying the kinetic parameters of prion replication, Biophys. Chem. (1999) 77:139-152.

[132] Mathiason C.K., Powers J.G., Dahmes S.J., Osborn D.A., Miller K.V., Warren R.J., et al., Infectious prions in the saliva and blood of deer with chronic wasting disease, Science (2006) 314:133-136.

[133] McGovern G., Jeffrey M., Scrapie-specific pathology of sheep lymphoid tissues, PLoS ONE (2007) 2:e1304.

[134] Meade-White K., Race B., Trifilo M., Bossers A., Favara C., Lacasse R., et al., Resistance to chronic wasting disease in transgenic mice expressing a naturally occurring allelic variant of deer prion protein, $\mathrm{J}$. Virol. (2007) 81:4533-4539.

[135] Miller M.W., Williams E.S., Prion disease: horizontal prion transmission in mule deer, Nature (2003) 425:35-36.

[136] Moreno C.R., Lantier F., Lantier I., Sarradin P., Elsen J.M., Detection of new quantitative trait loci for susceptibility to transmissible spongiform encephalopathies in mice, Genetics (2003) 165:20852091.

[137] Moum T., Olsaker I., Hopp P., Moldal T., Valheim M., Moum T., Benestad S.L., Polymorphisms at codons 141 and 154 in the ovine prion protein gene are associated with scrapie Nor98 cases, J. Gen. Virol. (2005) 86:231-235.

[138] Nentwig A., Oevermann A., Heim D., Botteron C., Zellweger K., Drögemuller C., et al., Diversity in neuroanatomical distribution of abnormal prion protein in atypical scrapie, PLoS Pathog. (2007) 3:e82.

[139] Noinville S., Chich J.F., Rezaei H., Misfolding of PrP protein: linking biophysical and biological approaches, Vet. Res. (2008) 39:48.

[140] Nonno R., Di Bari M.A., Cardone F., Vaccari G., Fazzi P., Dell'Omo G., et al., Efficient transmission and characterization of Creutzfeldt-Jakob disease strains in bank voles, PLoS Pathog. (2006) 2:e12.

[141] Orge L., Galo A., Machado C., Lima C., Ochoa C., Silva J., et al., Identification of putative atypical scrapie in sheep in Portugal, J. Gen. Virol. (2004) 85:3487-3491.

[142] O'Rourke K.I., Spraker T.R., Zhuang D., Greenlee J.J., Gidlewski T.E., Hamir A.N., Elk with a long incubation prion disease phenotype have a unique PrPd profile, Neuroreport. (2007) 18:1935-1938.

[143] Owen J.P., Rees H.C., Maddison B.C., Terry L.A., Thorne L., Jackman R., et al., Molecular profiling of ovine prion diseases by using thermolysinresistant PrPSc and endogenous C2 PrP fragments, J. Virol. (2007) 81:10532-10539.

[144] Pan K.M., Baldwin M., Nguyen J., Gasset M., Serban A., Groth D., et al., Conversion of alpha-helices into beta-sheets features in the formation of the scrapie 
prion proteins, Proc. Natl. Acad. Sci. USA (1993) 90:10962-10966.

[145] Pattison I.H., Gordon W.S., Millson G.C., Experimental production of scrapie in goats, J. Comp. Pathol. (1959) 69:300-312.

[146] Pattison I.H., Millson G.C., Scrapie produced experimentally in goats with special reference to the clinical syndrome, J. Comp. Pathol. (1961) 71:101109.

[147] Pattison I.H., Jones K.M., Modification of a strain of mouse-adapted scrapie by passage through rats, Res. Vet. Sci. (1968) 9:408-410.

[148] Peretz D., Scott M.R., Groth D., Williamson R.A., Burton D.R., Cohen F.E., et al., Strain-specified relative conformational stability of the scrapie prion protein, Protein Sci. (2001) 10:854-863.

[149] Peretz D., Williamson R.A., Legname G., Matsunaga Y., Vergara J., Burton D.R., et al., A change in the conformation of prions accompanies the emergence of a new prion strain, Neuron (2002) 34:921932 .

[150] Petkova A.T., Leapman R.D., Guo Z., Yau W.M., Mattson M.P., Tycko R., Self-propagating, molecularlevel polymorphism in Alzheimer's beta-amyloid fibrils, Science (2005) 307:262-265.

[151] Polak M.P., Zmudzinski J.F., Jacobs J.G., Langeveld J.P., Atypical status of bovine spongiform encephalopathy in Poland: a molecular typing study, Arch. Virol. (2008) 153:69-79.

[152] Priola S.A., Caughey B., Race R.E., Chesebro B., Heterologous PrP molecules interfere with accumulation of protease-resistant PrP in scrapie-infected murine neuroblastoma cells, J. Virol. (1994) 68:48734878.

[153] Prusiner S.B., Novel proteinaceous infectious particles cause scrapie, Science (1982) 216:136-144.

[154] Prusiner S.B., Cochran S.P., Groth D.F., Downey D.E., Bowman K.A., Martinez H.M., Measurement of the scrapie agent using an incubation time interval assay, Ann. Neurol. (1982) 11:353-358.

[155] Prusiner S.B., McKinley M.P., Bowman K.A., Bolton D.C., Bendheim P.E., Groth D.F., et al., Scrapie prions aggregate to form amyloid-like birefringent rods, Cell (1983) 35:349-358.

[156] Prusiner S.B., Scott M., Foster D., Pan K.M., Groth D., Mirenda C., et al., Transgenetic studies implicate interactions between homologous PrP isoforms in scrapie prion replication, Cell (1990) 63:673-686.

[157] Prusiner S.B., Prions, Proc. Natl. Acad. Sci. USA (1998) 95:13363-13383.

[158] Race R., Chesebro B., Scrapie infectivity found in resistant species, Nature (1998) 392:770.

[159] Race R., Raines A., Raymond G.J., Caughey B., Chesebro B., Long-term subclinical carrier state precedes scrapie replication and adaptation in a resistant species: analogies to bovine spongiform encephalopathy and variant Creutzfeldt-Jakob disease in humans, J. Virol. (2001) 75:10106-10112.

[160] Race R.E., Raines A., Baron T.G., Miller M.W., Jenny A., Williams E.S., Comparison of abnormal prion protein glycoform patterns from transmissible spongiform encephalopathy agent-infected deer, elk, sheep, and cattle, J. Virol. (2002) 76:12365-12368.

[161] Raymond G.J., Hope J., Kocisko D.A., Priola S.A., Raymond L.D., Bossers A., et al., Molecular assessment of the potential transmissibilities of BSE and scrapie to humans, Nature (1997) 388:285-288.

[162] Raymond G.J., Bossers A., Raymond L.D., O'Rourke K.I., McHolland L.E., Bryant P.K. 3rd, et al., Evidence of a molecular barrier limiting susceptibility of humans, cattle and sheep to chronic wasting disease, EMBO J. (2000) 19:4425-4430.

[163] Raymond G.J., Raymond L.D., Meade-White K.D., Hughson A.G., Favara C., Gardner D., et al., Transmission and adaptation of chronic wasting disease to hamsters and transgenic mice: evidence for strains, J. Virol. (2007) 81:4305-4314.

[164] Richt J.A., Kunkle R.A., Alt D., Nicholson E.M., Hamir A.N., Czub S., et al., Identification and characterization of two bovine spongiform encephalopathy cases diagnosed in the United States, J. Vet. Diagn. Invest. (2007) 19:142-154.

[165] Ridley R.M., Baker H.F., To what extent is strain variation evidence for an independent genome in the agent of the transmissible spongiform encephalopathies?, Neurodegeneration (1996) 5:219231.

[166] Rigter A., Bossers A., Sheep scrapie susceptibility-linked polymorphisms do not modulate the initial binding of cellular to disease-associated prion protein prior to conversion, J. Gen. Virol. (2005) 86:2627-2634.

[167] Saborio G.P., Permanne B., Soto C., Sensitive detection of pathological prion protein by cyclic amplification of protein misfolding, Nature (2001) 411:810 813.

[168] Sabuncu E., Petit S., Le Dur A., Lan Lai T., Vilotte J.L., Laude H., et al., PrP polymorphisms tightly control sheep prion replication in cultured cells, J. Virol. (2003) 77:2696-2700.

[169] Safar J., Wille H., Itri V., Groth D., Serban H., Torchia M., et al., Eight prion strains have $\mathrm{PrP}^{\mathrm{Sc}}$ molecules with different conformations, Nat. Med. (1998) 4:1157-1165.

[170] Safar J.G., Scott M., Monaghan J., Deering C., Didorenko S., Vergara J., et al., Measuring prions causing bovine spongiform encephalopathy or chronic wasting disease by immunoassays and transgenic mice, Nat. Biotechnol. (2002) 20:1147-1150.

[171] Safar J.G., Geschwind M.D., Deering C., Didorenko S., Sattavat M., Sanchez H., et al., 
Diagnosis of human prion disease, Proc. Natl. Acad. Sci. USA (2005) 102:3501-3506.

[172] Safar J.G., Kellings K., Serban A., Groth D., Cleaver J.E., Prusiner S.B., et al., Search for a prionspecific nucleic acid, J. Virol. (2005) 79:10796-10806.

[173] Scott M., Foster D., Mirenda C., Serban D., Coufal F., Wälchli M., et al., Transgenic mice expressing hamster prion protein produce species-specific scrapie infectivity and amyloid plaques, Cell (1989) 59:847-857.

[174] Scott M.R., Groth D., Tatzelt J., Torchia M., Tremblay P., DeArmond S.J., et al., Propagation of prion strains through specific conformers of the prion protein, J. Virol.(1997) 71:9032-9044.

[175] Scott M.R., Will R., Ironside J., Nguyen H.O., Tremblay P., DeArmond S.J., et al., Compelling transgenetic evidence for transmission of bovine spongiform encephalopathy prions to humans, Proc. Natl. Acad. Sci. USA (1999) 96:15137-15142.

[176] Scott M.R., Peretz D., Nguyen H.O., Dearmond S.J., Prusiner S.B., Transmission barriers for bovine, ovine, and human prions in transgenic mice, J. Virol. (2005) 79:5259-5271.

[177] Seuberlich T., Botteron C., Wenker C., CaféMarçal V.A., Oevermann A., Haase B., et al., Spongiform encephalopathy in a miniature zebu, Emerging Infect. Dis. (2006) 12:1950-1953.

[178] Sigurdson C.J., Williams E.S., Miller M.W., Spraker T.R., O'Rourke K.I., Hoover E.A., Oral transmission and early lymphoid tropism of chronic wasting disease $\mathrm{PrP}^{\mathrm{res}}$ in mule deer fawns (Odocoileus hemionus), J. Gen. Virol. (1999) 80:2757-2764.

[179] Sigurdson C.J., Manco G., Schwarz P., Liberski P., Hoover E.A., Hornemann S., et al., Strain fidelity of chronic wasting disease upon murine adaptation, $\mathrm{J}$. Virol. (2006) 80:12303-12311.

[180] Sigurdson C.J., Nilsson K.P., Hornemann S., Manco G., Polymenidou M., Schwarz P., et al., Prion strain discrimination using luminescent conjugated polymers, Nat. Methods (2007) 4:1023-1030.

[181] Sigurdson C.J., A prion disease of cervids: chronic wasting disease, Vet Res (2008) 39:41.

[182] Silveira J.R., Raymond G.J., Hughson A.G., Race R.E., Sim V.L., Hayes S.F., et al., The most infectious prion protein particles, Nature (2005) 437:257261.

[183] Simmons M.M., Konold T., Simmons H.A., Spencer Y.I., Lockey R., Spiropoulos J., et al., Experimental transmission of atypical scrapie to sheep, BMC Vet. Res. (2007) 3:20.

[184] Somerville R.A., Ritchie L.A., Differential glycosylation of the protein (PrP) forming scrapieassociated fibrils, J. Gen. Virol. (1990) 71:833-839.

[185] Somerville R.A., Oberthur R.C., Havekost U., MacDonald F., Taylor D.M., Dickinson A.G.,
Characterization of thermodynamic diversity between transmissible spongiform encephalopathy agent strains and its theoretical implications, J. Biol. Chem. (2002) 277:11084-11089.

[186] Spassov S., Beekes M., Naumann D., Structural differences between TSEs strains investigated by FT-IR spectroscopy, Biochim. Biophys. Acta (2006) 1760:1138-1149.

[187] Surewicz W.K., Jones E.M., Apetri A.C., The emerging principles of mammalian prion propagation and transmissibility barriers: insight from studies in vitro, Acc. Chem. Res. (2006) 39:654-662.

[188] Tamgüney G., Giles K., Bouzamondo-Bernstein E., Bosque P.J., Miller M.W., Safar J., et al., Transmission of elk and deer prions to transgenic mice, J. Virol. (2006) 80:9104-9114.

[189] Tanaka M., Chien P., Yonekura K., Weissman J.S., Mechanism of cross-species prion transmission: an infectious conformation compatible with two highly divergent yeast prion proteins, Cell (2005) 121:49-62.

[190] Telling G.C., Scott M., Mastrianni J., Gabizon R., Torchia M., Cohen F.E., et al., Prion propagation in mice expressing human and chimeric PrP transgenes implicates the interaction of cellular PrP with another protein, Cell (1995) 83:79-90.

[191] Terry L.A., Marsh S., Ryder S.J., Hawkins S.A., Wells G.A., Spencer Y.I., Detection of disease-specific PrP in the distal ileum of cattle exposed orally to the agent of bovine spongiform encephalopathy, Vet. Rec.(2003) 152:387-392.

[192] Terry L.A., Jenkins R., Thorne L., Everest S.J., Chaplin M.J., Davis L.A., et al., First case of H-type bovine spongiform encephalopathy identified in Great Britain, Vet. Rec. (2007) 160:873-874.

[193] Tessier P.M., Lindquist S., Prion recognition elements govern nucleation, strain specificity and species barriers, Nature (2007) 447:556-561.

[194] Trifilo M.J., Ying G., Teng C., Oldstone M.B., Chronic wasting disease of deer and elk in transgenic mice: oral transmission and pathobiology, Virology (2007) 365:136-143.

[195] Valleron A.J., Boelle P.Y., Will R., Cesbron J.Y., Estimation of epidemic size and incubation time based on age characteristics of vCJD in the United Kingdom, Science (2001) 294:1726-1728.

[196] Vanik D.L., Surewicz K.A., Surewicz W.K., Molecular basis of barriers for interspecies transmissibility of mammalian prions, Mol. Cell (2004) 14:139_ 145 .

[197] Vilotte J.L., Soulier S., Essalmani R., Stinnakre M.G., Vaiman D., Lepourry L., et al., Markedly increased susceptibility to natural sheep scrapie of transgenic mice expressing ovine PrP, J. Virol. (2001) 75:5977-5984. 
[198] Vorberg I., Priola S.A., Molecular basis of scrapie strain glycoform variation, J. Biol. Chem. (2002) 277:36775-36781.

[199] Vorberg I., Groschup M.H., Pfaff E., Priola S.A., Multiple amino acid residues within the rabbit prion protein inhibit formation of its abnormal isoform, J. Virol. (2003) 77:2003-2009.

[200] Wadsworth J.D., Joiner S., Hill A.F., Campbell T.A., Desbruslais M., Luthert P.J., et al., Tissue distribution of protease resistant prion protein in variant Creutzfeldt-Jakob disease using a highly sensitive immunoblotting assay, Lancet (2001) 358:171-180.

[201] Wadsworth J.D., Asante E.A., Desbruslais M., Linehan J.M., Joiner S., Gowland I., et al., Human prion protein with valine 129 prevents expression of variant CJD phenotype, Science (2004) 306:17931796.

[202] Wadsworth J.D., Collinge J., Update on human prion disease, Biochim. Biophys. Acta (2007) 1772:598-609.

[203] Westaway D., DeArmond S.J., Cayetano-Canlas J., Groth D., Foster D., Yang S.L., et al., Degeneration of skeletal muscle, peripheral nerves, and the central nervous system in transgenic mice overexpressing wild-type prion proteins, Cell (1994) 76:117-129.

[204] Wilesmith J.W., Ryan J.B., Atkinson M.J., Bovine spongiform encephalopathy: epidemiological studies on the origin, Vet. Rec. (1991) 128:199-203.

[205] Will R.G., Ironside J.W., Zeidler M., Cousens S.N., Estibeiro K., Alperovitch A., et al., A new variant of Creutzfeldt-Jakob disease in the UK, Lancet (1996) 347:921-925.
[206] Windl O., Buchholz M., Neubauer A., SchulzSchaeffer W., Groschup M., Walter S., et al., Breaking an absolute species barrier: transgenic mice expressing the mink PrP gene are susceptible to transmissible mink encephalopathy, J. Virol. (2005) 79:1497114975.

[207] Wong C., Xiong L.W., Horiuchi M., Raymond L., Wehrly K., Chesebro B., et al., Sulfated glycans and elevated temperature stimulate $\mathrm{PrP}^{\mathrm{Sc}}$-dependent cell-free formation of protease-resistant prion protein, EMBO J. (2001) 20:377-386.

[208] Wüthrich K., Riek R., Three-dimensional structures of prion proteins, Adv. Protein Chem. (2001) 57:55-82.

[209] Xie Z., O’Rourke K.I., Dong Z., Jenny A.L., Langenberg J.A., Belay E.D., et al., Chronic wasting disease of elk and deer and Creutzfeldt-Jakob disease: comparative analysis of the scrapie prion protein, J. Biol. Chem. (2006) 281:4199-4206.

[210] Yedidia Y., Horonchik L., Tzaban S., Yanai A., Taraboulos A., Proteasomes and ubiquitin are involved in the turnover of the wild-type prion protein, EMBO J. (2001) 20:5383-5391.

[211] Zanusso G., Casalone C., Acutis P., Bozzetta E., Farinazzo A., Gelati M., et al., Molecular analysis of iatrogenic scrapie in Italy, J. Gen. Virol. (2003) 84:1047-1052.

[212] Zlotnik I., Rennie J.C., Further observations on the experimental transmission of scrapie from sheep and goats to laboratory mice, J. Comp. Pathol. (1963) 73:150-162.

[213] Zlotnik I., Rennie J.C., Experimental transmission of mouse passaged scrapie to goats, sheep, rats and hamsters, J. Comp. Pathol. (1965) 75:147-157. 